\title{
Therapeutic Potentials of Colocasia affinis Leaf Extract for the Alleviation of Streptozotocin-Induced Diabetes and Diabetic Complications: In vivo and in silico-Based Studies
}

This article was published in the following Dove Press journal:

Journal of Inflammation Research

\author{
Manik Chandra Shill (1D) \\ Asim Kumar Bepari $\mathbb{I D}^{\prime}$ \\ Mahi Khan' \\ Zarin Tasneem' \\ Tania Ahmed' \\ Md Asif Hasan (I) \\ Md Jahir Alam' \\ Murad Hossain' \\ Md Ashrafur \\ Rahman (D)' \\ Shazid Md Sharker (D) \\ Masum Shahriar ${ }^{2}$ \\ Ghazi Muhammad Sayedur \\ Rahman' \\ Hasan Mahmud Reza' \\ 'Department of Pharmaceutical Sciences, \\ North South University, Bashundhara, \\ Dhaka, 1229, Bangladesh; ${ }^{2}$ Department \\ of Pharmacy, Jahangirnagar University, \\ Savar, Bangladesh
}

\begin{abstract}
Introduction: Hypoglycemia in diabetes mellitus (DM) correlates with hepatic impairment, nephropathy, lipid abnormalities, and oxidative stress and subsequently complicates the disease pathogenesis. Medicinal plants have been used for the management of diabetes since ancient times. In this study, we explored the potentials of Colocasia affinis (CA), a plant known to possess antiallergic and anti-inflammatory activities, as a remedy for diabetes and related complications.

Methods: We induced diabetes in rats using a single intraperitoneal dose $(65 \mathrm{mg} / \mathrm{kg})$ of streptozotocin (STZ). We next treated the rats with an ethanolic extract of leaves of CA to reveal its antidiabetic and organ-protective potentials. Biomarkers of diabetes, inflammation, and oxidative stress were measured using biochemical and histopathological analysis. We also performed molecular docking for three major phytochemicals (kaempferol, myricetin, and rosmarinic acid) of CA.
\end{abstract}

Results: Oral administration of the CA leaves extract at $250 \mathrm{mg} / \mathrm{kg}$ and $500 \mathrm{mg} / \mathrm{kg} \mathrm{doses}$ decreased blood glucose level significantly $(p<0.05)$ in STZ-induced diabetic rats. The extract also considerably attenuated plasma HbAlc levels and normalized blood lipids, glycogen, alanine aminotransferase (ALT), and aspartate aminotransferase (AST). Additionally, treatment with the extract improved kidney complications by decreasing serum creatinine and blood urea nitrogen (BUN) levels. Furthermore, CA leaves extract normalized nitric oxide (NO) and advance oxidative protein products (AOPP) in diabetic rats. The extract also showed significant improvement of the antioxidant enzymes glutathione dismutase (GSH) and superoxide dismutase (SOD) at a dose of $500 \mathrm{mg} / \mathrm{kg}$. Besides, histological investigation demonstrated attenuation of inflammation of the vital organs, including the liver and the kidney. In silico studies revealed that three major phytochemicals (kaempferol, myricetin, and rosmarinic acid) of the ethanolic extract of leaves of CA can inhibit several molecular targets of diabetes and inflammation.

Conclusion: Collectively, our results demonstrated the therapeutic potentials of CA for the mitigation of diabetes and diabetic complications.

Keywords: diabetes mellitus, Colocasia affinis, antidiabetic potentials, vital organs protection, oxidative stress markers

\section{Introduction}

Diabetes mellitus (DM) is one of the appalling global public health issues. The World Health Organization (WHO) estimated that approximately $9 \%$ of the Bangladeshi populations are exposed to diabetes and its complications. ${ }^{1-3}$
Correspondence: Manik Chandra Shill; Hasan Mahmud Reza

Department of Pharmaceutical Sciences, North South University, Bashundhara, Dhaka, 1229, Bangladesh

Email manik.shill@northsouth.edu; hasan. reza@northsouth.edu
Journal of Inflammation Research 2021:14 443-459

443

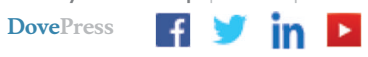

(c) (i) (5) 2021 Shill et al. This work is published and licensed by Dove Medical Press Limited. The full terms of this license are available at https://www.dovepress.com/terms.php cc) and incorporate the Creative Commons Attribution - Non Commercial (unported, v3.0) License (http:///creativecommons.org/licenses/by-nc/3.0/). By accessing the work you hereby accept the Terms. Non-commercial uses of the work are permitted without any further permission from Dove Medical Press
permission for commercial use of this work, please see paragraphs 4.2 and 5 of our Terms (https://www.dovepress.com/terms php). 
Diabetes is considered an inflammatory disease characterized by insulin resistance and high blood glucose levels, which correlate with hepatic impairment, nephropathy, irregular serum lipid profile, and elevated oxidative stress markers. ${ }^{4-10}$ Streptozotocin (STZ), an alkylating agent, is widely used in generating animal models of impaired pancreatic beta-cells, insulin resistance, and diabetes. Consequently, serum glucose levels increase remarkably, and surplus glucose responds to hemoglobin to elevate glycosylated hemoglobin (HbA1c). ${ }^{4,8,11}$ Cumulative evidence suggests that the molecules that attenuate serum glucose level, HbA1c, inflammation, and oxidative stress can improve diabetic complications.

Medicinal plants have been used worldwide for thousands of years and remain a good source for modern medicines. $^{12}$ The plant Colocasia affinis (CA) grows in several parts of Bangladesh. A few recent works reported hypoglycemic, anti-allergic, and antiinflammatory effects of CA. ${ }^{13,14}$ Interestingly, a growing number of studies suggest that compounds demonstrating anti-inflammatory potentials can ameliorate diabetes and its complications. ${ }^{15}$ In this study, we evaluated the antidiabetic effects and therapeutic efficacy of the leaves extract of CA in STZ-induced diabetic rats. Moreover, we performed in silico analyses to demonstrate the binding of the phytoconstituents of CA and glibenclamide with known mediators of diabetes and diabetic complications.

\section{Materials and Methods}

\section{Chemicals}

We purchased streptozotocin (STZ) and thiobarbituric acid (TBA) from Sigma-Aldrich (Germany). Reduced glutathione (GSH) was obtained from J.I. Baker (USA). We purchased total cholesterol (TC), triglyceride (TG), HDL, LDL, aspartate transaminase (AST), alanine transaminase (ALT), serum creatinine, and BUN diagnostic kits from HUMAN GmbH (Germany). All other chemicals, solvents, and reagents used in the present study were of analytical grade.

\section{Plant Collection and Extraction}

Colocasia affinis (CA) leaves were collected from Khulna, Bangladesh, authenticated from National Herbarium, Dhaka, Bangladesh, and a voucher specimen was deposited. Plant materials were shade-dried, ground, cooled, extracted with ethanol, and finally concentrated using a rotary evaporator (EYELA, Model: N-1200B, Japan) and stored in the refrigerator until further use.

\section{Experimental Animals}

We obtained ethical clearance (2020/OR-NSU/IACUCNo.0801) from the Institutional Animal Care and Use Committee (IACUC), North South University. We followed guidelines stipulated by the Council for International Organization of Medical Sciences and The International Council for Laboratory Animal Science (CIOMS/ICLAS, 2012) and the Nuffield Council on Bioethics (NCB). Sprague Dawley rats of either sex, 6-8-week-aged, weighing 180 to $200 \mathrm{~g}$, were acclimatized under standard conditions such as 12 h light-dark cycle, $22 \pm 2{ }^{\circ} \mathrm{C}$ temperature, and $55 \%$ humidity. We provided standard pellet diets and pure drinking water to the rats throughout the experiment.

\section{Induction of Diabetes}

We induced type-1 diabetes in the experimental rodents using a previously established method. ${ }^{16}$ Briefly, we prepared streptozotocin (STZ) in $0.5 \mathrm{M}$ citrate buffer $(\mathrm{pH} 4.5)$ and administered the freshly prepared STZ to overnight starved rats at a $65 \mathrm{mg} / \mathrm{kg}$ b.w. dose. One week later, rats revealing fasting blood glucose levels of $8-12 \mathrm{mmol} / \mathrm{L}$ were included in subsequent experiments.

\section{Experimental Design}

Thirty rats were grouped into five, with each group comprised of six rats.

In the control group, the rats received $2 \%$ carboxymethyl cellulose (CMC) in water. The STZ group received $65 \mathrm{mg} /$ $\mathrm{kg} \mathrm{BW}$ of STZ (intraperitoneal) and vehicle (oral gavage). Other groups received $65 \mathrm{mg} / \mathrm{kg} \mathrm{BW}$ of STZ (intraperitoneal) and either glibenclamide $10 \mathrm{mg} / \mathrm{kg}$ (STZ + GLI), CA $250 \mathrm{mg} / \mathrm{kg}$ (STZ + CA 250), or CA $500 \mathrm{mg} / \mathrm{kg}$ (STZ + CA $500)$. CA was suspended in $2 \% \mathrm{CMC}$ in pure water and each rat received $1 \mathrm{~mL}$ freshly prepared suspension.

The total treatment period was 28 days. Subsequently, blood samples were collected from rats in heparinized tubes, animals were euthanized to death using ketamine (300 mg/kg b.w.) with a slight modification of a previous method, ${ }^{17}$ and organs were collected. All the samples were well-preserved for further analysis. 


\section{Estimation of Blood Glucose}

We collected venous blood from the rat tails by sterile needle pricks and measured blood glucose levels on the day $0,7,14,21$, and 28 using a commercial glucometer (Accu-Chek, USA).

\section{Assessment of Glycosylated Hemoglobin ( $\mathrm{HbAlc})$}

We measured HbAlc on the 28th day using a semi-auto blood analyzer (Humalyzer 3000, Germany) according to the manufacturer's protocol.

\section{Estimation of Plasma Biochemical Markers}

Blood samples were centrifuged for 15 minutes at $8000 \mathrm{rpm}$ in a controlled environment (at 2 to $4{ }^{\circ} \mathrm{C}$ ), and the plasma was collected and stored at $-20{ }^{\circ} \mathrm{C}$ until further investigation. Further, we analyzed plasma samples for biochemical markers including TC, TG, HDL, LDL, AST, ALT, serum creatinine, and BUN using LiquiUV diagnostic kits (HUMAN GmbH, Germany) and an Erba Chem v3 semi-auto biochemistry analyzer.

\section{Estimation of Liver Glycogen}

We measured liver glycogen according to a previous method. ${ }^{18}$ In short, $1 \mathrm{~g}$ of the fresh liver was taken in a test tube, $\mathrm{KOH}$ was added, heated to boiling in a water bath for 30 minutes. Then, $4 \mathrm{~mL}$ of ethanol was added, mixed thoroughly, cooled, centrifuged at 3000 RPM, and the pellet was separated and resuspended in distilled water. Next, the anthrone reagent was added, and the intensity of green color was measured at $620 \mathrm{~nm}$. Blank and standard glucose solutions were prepared following the same procedure. The amount of liver glycogen was estimated using the following formula:

Liver glycogen $=\frac{U \times 100}{S \times 1.11} \mathrm{mg} / \mathrm{g}$ of liver.

Where, $\mathrm{U}=$ the optical density of test sample, $\mathrm{S}=$ the optical density of glucose solution and $1.11=$ the factor for the conversion of glucose to glycogen.

\section{Tissue Homogenate Preparation and Investigation of Oxidative Stress Markers} Samples were prepared by homogenization of $1 \mathrm{~g}$ liver and kidney tissue in $10 \mathrm{~mL}$ of phosphate buffer $(\mathrm{pH}$
7.4) and subsequent centrifugation at $8000 \mathrm{rpm}$ for 15 min at $4{ }^{\circ} \mathrm{C}$. The supernatant was stored at $-20^{\circ} \mathrm{C}$ for future analysis. We determined nitric oxide (NO) levels and advanced oxidative protein products (AOPP) as oxidative stress markers. According to a previous method, ${ }^{19}$ we evaluated NO against the corresponding blank solutions (absorbance measured at $540 \mathrm{~nm}$ ). The level of NO was calculated as $\mathrm{nmol} / \mathrm{g}$ of tissue from a standard curve. AOPP levels were measured by an earlier method, ${ }^{20,21}$ with minor modifications. Shortly, to $5 \mu \mathrm{L}$ of the sample, we added $95 \mu \mathrm{L}$ PBS and $50 \mu \mathrm{L}$ of acetic acid and potassium iodide and incubated for 2 minutes. The final reading was measured at $340 \mathrm{~nm}$. Blank reading was measured using PBS $(100 \mu \mathrm{L})$ and $50 \mu \mathrm{L}$ acetic acid and potassium iodide. We finally calculated AOPP levels from chloramine-T linear chart at $340 \mathrm{~nm}$ (concentrations of chloramine- $\mathrm{T}$ ranged from 0 to $100 \mathrm{nmol} / \mathrm{mL}$ ).

\section{Study of Antioxidant Activities}

Superoxide dismutase (SOD) and reduced glutathione (GSH) are two potent antioxidant enzymes. We analyzed liver and kidney tissue homogenates for the SOD activities by an established method. ${ }^{22}$ Shortly, we added $90 \mu \mathrm{L}$ PBS, $10 \mu \mathrm{L}$ tissue supernatants, and 100 $\mu \mathrm{L}$ epinephrine in the 96-well plates. Next, we recorded optical density (OD) at $480 \mathrm{~nm}$ at different time intervals, and differences were calculated. We also ran a blank containing all the constituents except the enzyme. To measure GSH levels, we added $90 \mu \mathrm{L}$ PBS and $100 \mu \mathrm{L}$ DTNB to $10 \mu \mathrm{L}$ tissue homogenate and the absorbance was instantly measured at $412 \mathrm{~nm}$ once the yellow color was formed. ${ }^{21,23}$

\section{Histopathological Examination}

After the experiment, rats were euthanized and liver and kidney tissues were harvested in $10 \%$ buffered formalin. Next, we embedded the tissue blocks in paraffin, sliced at a $5 \mu \mathrm{m}$ thickness, and stained with hematoxylin/eosin. All the stained samples were examined at 40X magnification under a light microscope (Zeiss Axioscope).

\section{In silico Analysis}

The X-ray crystallographic protein structures used in this study are listed in Table 1. Protein Data Bank (PDB) files were retrieved from the Protein Data Bank (https://www. 
Table I Estimated Free Energy of Binding and Inhibition Constant of Major Plant Constituents for Potential Molecular Targets of Diabetes and Inflammation

\begin{tabular}{|c|c|c|c|c|c|c|c|}
\hline \multirow[b]{2}{*}{ Protein } & \multirow[b]{2}{*}{ PDB ID } & \multicolumn{2}{|c|}{ Kaempferol } & \multicolumn{2}{|c|}{ Myricetin } & \multicolumn{2}{|c|}{ Rosmarinic Acid } \\
\hline & & $\Delta \mathbf{G}$ & $\mathbf{K i}$ & $\Delta \mathbf{G}$ & $\mathbf{K i}$ & $\Delta \mathbf{G}$ & $\mathbf{K i}$ \\
\hline AKRIC3 & $4 Y V V$ & -7.56 & $2.86 \mu \mathrm{M}$ & -7.58 & $2.77 \mu \mathrm{M}$ & -8.66 & $451.37 \mathrm{nM}$ \\
\hline cox-I & $4 O I Z$ & -6.74 & I I. $48 \mu \mathrm{M}$ & -6.33 & $22.96 \mu \mathrm{M}$ & -8.57 & $525.4 \mathrm{nM}$ \\
\hline COX-2 & $5 I K R$ & -7.17 & $5.53 \mu \mathrm{M}$ & -6.33 & $23 \mu \mathrm{M}$ & -7.3 & $4.44 \mu \mathrm{M}$ \\
\hline DPP4 & $6 \mathrm{BIE}$ & -6.05 & $37.05 \mu \mathrm{M}$ & -5.72 & $64.63 \mu \mathrm{M}$ & -5.56 & $84.39 \mu \mathrm{M}$ \\
\hline GLUTI & $5 E Q G$ & -7.56 & $2.89 \mu \mathrm{M}$ & -7.18 & $5.42 \mu \mathrm{M}$ & -6.71 & $12.12 \mu \mathrm{M}$ \\
\hline ILIRI & IGOY & -7.79 & $1.93 \mu \mathrm{M}$ & -7.85 & $\mathrm{I} .75 \mu \mathrm{M}$ & $-6.7 \mid$ & $12.01 \mu \mathrm{M}$ \\
\hline PPAR-gamma & $2 X K W$ & -6.98 & $7.61 \mu M$ & -7.08 & $6.45 \mu \mathrm{M}$ & -6.6 & $14.64 \mu \mathrm{M}$ \\
\hline SURI & 6BAA & -6.3 & $23.8 \mu \mathrm{M}$ & -6.1 & $35.19 \mu \mathrm{M}$ & -7.05 & $6.79 \mu \mathrm{M}$ \\
\hline TNF-alpha & 5MU8 & -6.55 & $15.88 \mu \mathrm{M}$ & -6.74 & $1 \mathrm{I} .54 \mu \mathrm{M}$ & -5.85 & $5 \mathrm{I} .4 \mu \mathrm{M}$ \\
\hline
\end{tabular}

Abbreviations: $\Delta \mathrm{G}$, estimated free energy of binding $(\mathrm{kcal} / \mathrm{mol})$; $\mathrm{Ki}$, estimated inhibition constant.

rcsb.org/). Structures of kaempferol, myricetin, and rosmarinic acid were downloaded as SDF files from PubChem (https://pubchem.ncbi.nlm.nih.gov/) and DrugBank (https://go.drugbank.com/). Ligands were prepared for docking using Open $\mathrm{Babel}^{24}$ and the ligand preparation module of Parallelized Open Babel \& Autodock suite Pipeline (POAP). ${ }^{25}$

We performed molecular docking using AutoDock 4.2. ${ }^{26}$ A single chain from the PDB file was selected and processed using UCSF Chimera version 1.13.1 and prepared for rigid docking using AutoDock Tools. ${ }^{26}$ We selected the best conformation exhibiting the minimum estimated free energy of binding $(\Delta \mathrm{G}, \mathrm{kcal} / \mathrm{mol})$ and recorded the corresponding inhibition constant (Ki). We analyzed protein-ligand interactions using Discovery Studio Visualizer (BIOVIA, Dassault Systèmes, Discovery Studio Visualizer, v20.1.0.192, 2019). Images were rendered using AutoDock Tools and Discovery Studio Visualizer.

\section{Statistical Analysis}

We have presented our data as means \pm standard errors of the means (SEM). For the evaluation of statistical significance we used one-way ANOVA and Newman-Keuls post hoc tests with the Graph Pad Prism Software (USA). $\mathrm{P}<0.05$ was considered statistically significant in all experiments.

\section{Results}

\section{Effect of CA on Glycemic Control and Body Weight}

Fasting blood glucose and glycosylated hemoglobin (HbAlc) are the most common and significant markers to measure diabetes. ${ }^{4,8,11}$ In our experiment, intraperitoneal streptozotocin (STZ) administration increased blood glucose levels in the experimental rats. Treatment with the ethanol extract of CA reduced fasting blood glucose levels dose-dependently at different timelines. Details are described in Table 2. The glucose-lowering

Table 2 Effect of CA in the Glycemic Control on Diabetic Rats at Different Time Intervals. Data are Expressed as Means \pm S.E.M; a= STZ vs Control $(P<0.000 I)$; $b=S T Z$ vs STZ+GLI $(P<0.000 I) ; c=S T Z$ vs STZ+CA250 (P<0.000I); $d=S T Z$ vs $S T Z+C A 500$ (P<0.000I) $(n=6)$

\begin{tabular}{|l|c|c|c|c|c|}
\hline Groups & Day I & Day 7 & Day 14 & Day 2I & Day 28 \\
\hline Control & $5.23 \pm 0.18$ & $5.32 \pm 0.18$ & $5.30 \pm 0.15$ & $5.25 \pm 0.22$ & $5.23 \pm 0.18$ \\
STZ & $8.33 \pm 0.10$ & $8.27 \pm 0.17^{\mathrm{a}}$ & $14.17 \pm 0.70^{\mathrm{a}}$ & $16.88 \pm 0.93^{\mathrm{a}}$ & $15.33 \pm 0.92^{\mathrm{a}}$ \\
STZ+GLI & $9.15 \pm 0.47$ & $8.52 \pm 0.47$ & $7.52 \pm 0.53^{\mathrm{b}}$ & $6.47 \pm 0.27^{\mathrm{b}}$ & $5.85 \pm 0.20^{\mathrm{b}}$ \\
STZ+CA250 & $8.07 \pm 0.05$ & $7.80 \pm 0.12$ & $14.05 \pm 0.62$ & $11.02 \pm 0.48^{\mathrm{c}}$ & $8.38 \pm 0.39^{\mathrm{c}}$ \\
STZ+CA500 & $8.10 \pm 0.12$ & $7.58 \pm 0.12$ & $12.48 \pm 0.52$ & $9.55 \pm 0.34^{\mathrm{d}}$ & $7.55 \pm 0.22^{\mathrm{d}}$ \\
\hline
\end{tabular}

Note: Blood glucose is estimated as $\mathrm{mmol} / \mathrm{dl}$.

Abbreviations: STZ, streptozotocin; Gli, glibenclamide; CA, Colocasia affinis; mmol, millimole; dl, deciliter. 


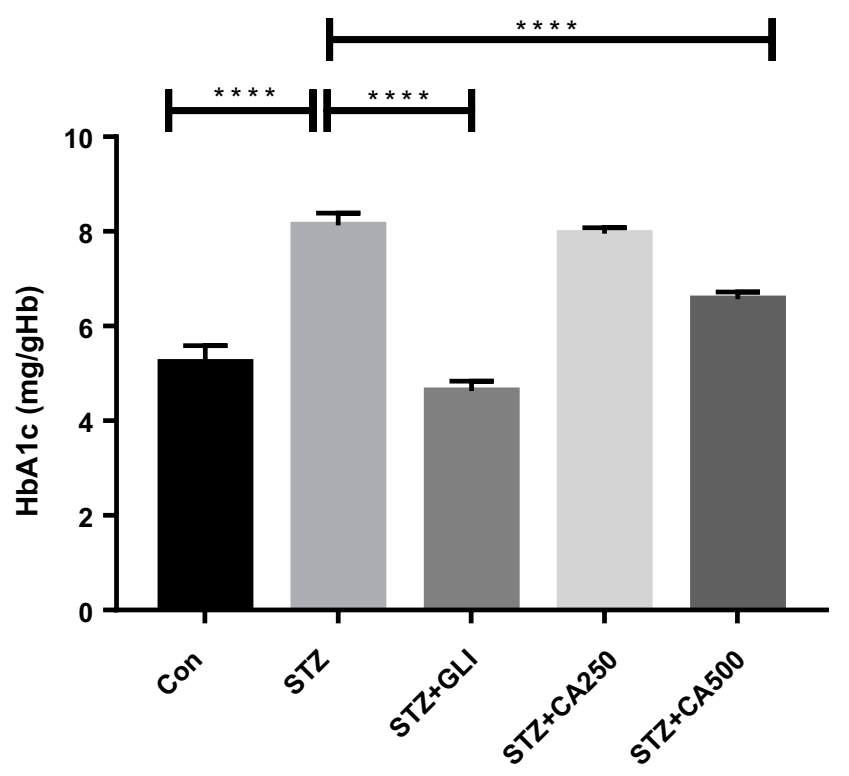

Figure I Therapeutic potential of CA on $\mathrm{HbAlc}$ management in the diabetic rats. We used glibenclamide as a standard drug to compare the results. Data are expressed as means \pm S.E.M.; ${ }^{* * * *} p \leq 0.0000$ I vs control or STZ-induced diabetic rats $(n=6)$. Abbreviations: CA, Colocasia affinis; Gli, glibenclamide; HbAlc, glycated haemoglobin; STZ, streptozotocin.

efficacy of glibenclamide and CA became apparent from the second week of the treatment. At the end of the experiment $\left(28^{\text {th }}\right.$ day), CA showed a comparable glucoselowering effect with the standard drug glibenclamide (Table 2). CA also attenuated the levels of HbAlc dosedependently in the diabetic rats and showed a significant reduction $(\mathrm{p}<0.0001)$ of $\mathrm{HbAlc}$ at a dose of $500 \mathrm{mg} / \mathrm{kg}$ (Figure 1). Moreover, oral treatment with CA significantly $(p<0.0001)$ increased in the body weight of the diabetic rats (Figure 2). These results demonstrated the capacity of CA leaves extract in the glycemic control of diabetic animals.

\section{Effect of CA on Lipid Profiles}

Diabetes is inversely associated with lipid abnormalities..$^{9,27,28}$ We measured plasma lipid levels to evaluate the lipid-lowering efficacy of CA leaves extract in diabetic rats. STZ administration increased serum triglyceride (TG) significantly in the experimental rats compared to the control animals ( $p<0.00001)$. Subsequent oral administration of the $\mathrm{CA}$ leaves extract, both $250 \mathrm{mg} / \mathrm{kg}(\mathrm{p}<0.001)$ and $500 \mathrm{mg} / \mathrm{kg}(\mathrm{p}$ $<0.00001$ ) doses, showed significant reductions of TG levels in the treatment group as depicted in Figure 3A.
Similar results were also obtained for total cholesterol (TC) levels, where both doses of CA normalized TC ( $p$ $<0.00001)$ in the diabetic rats as described in Figure 3B. Moreover, oral administration of CA leaves extract showed promising results in reducing low-density lipoprotein (LDL) $(250 \mathrm{mg} / \mathrm{kg}, \mathrm{p}<0.001 ; 500 \mathrm{mg} / \mathrm{kg}$, $\mathrm{p}<0.00001$ ), which is comparable to the glibenclamide treatment Figure 3C.

Our data also elucidated that the administration of STZ decreased high-density lipoprotein (HDL) in the experimental rodents compared to the control group ( $\mathrm{p}$ $<0.0001)$. At the same time, oral gavage of the CA leaves extracts dose-dependently increased HDL level in the diabetic rats Figure 3D. Our data demonstrated that the CA leaves extract at the $500 \mathrm{mg} / \mathrm{kg}$ dose significantly $(\mathrm{p}<0.05)$ improved the experimental animals' lipid levels.

\section{Effect of CA on Liver Functions}

Intra-peritoneal administration of STZ induces hepatic impairment. Hepatic impairment increases serum ALT and AST activities, ${ }^{29}$ and therefore, we quantified the levels of these enzymes in the experimental animals. The effect of CA in liver enzyme activities is illustrated in Figure 4. Plasma ALT level was significantly ( $p<0.00001)$ increased in STZ-induced diabetic rats compared to the control rats. The oral administration of CA at a dose of 250 or $500 \mathrm{mg} / \mathrm{kg}$ significantly reduced the ALT level in the diabetic rats ( $p$ $<0.00001$ ). Again, oral gavage of CA at a dose of $500 \mathrm{mg} / \mathrm{kg}$ normalized ALT activities, which were comparable with glibenclamide as depicted in Figure 4A. Similarly, oral administration of CA leaves extract at 250 or $500 \mathrm{mg} / \mathrm{kg}$ of body weight normalized AST enzyme activities $(p<0.00001)$ in the diabetic rats, which was analogous with that of the standard drug (glibenclamide) group Figure 4B. Moreover, administration of STZ significantly lowered the liver glycogen level $(\mathrm{p}<0.00001)$ in diabetic rodents. Subsequently, oral treatment with $\mathrm{CA}$ at $500 \mathrm{mg} / \mathrm{kg}$ significantly increased glycogen level ( $p<0.00001)$, and the effect was comparable with the glibenclamide treatment, as shown in Figure 4C. CA at $250 \mathrm{mg} / \mathrm{kg}$ did not have any effect on glycogen levels in diabetic rats. 


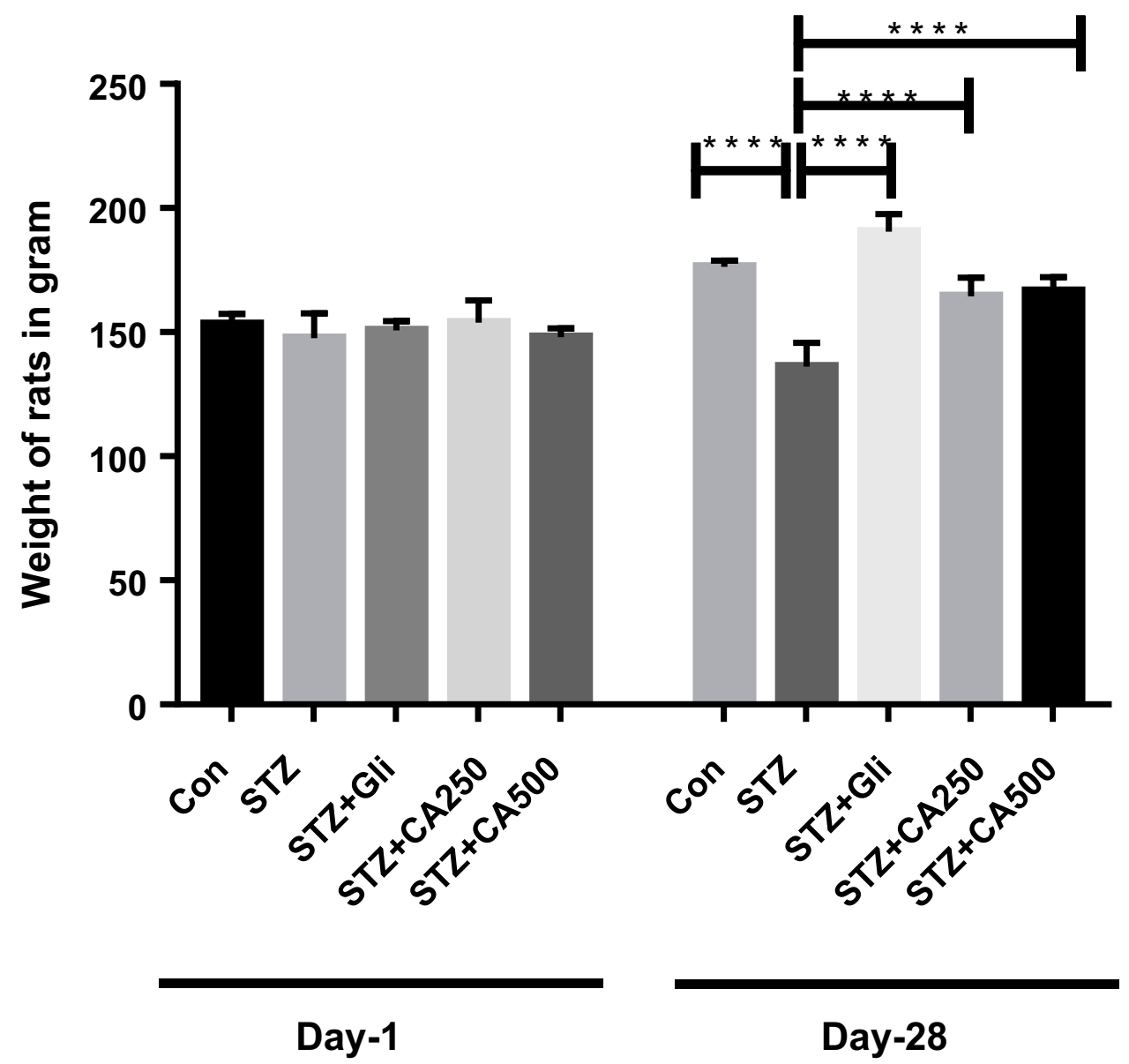

Figure 2 Effect of CA on body weight in the diabetic rats. We used glibenclamide as a standard drug to compare the results. Data are expressed as means \pm S.E.M.; ***** $\leq$ 0.00001 vs control or STZ-induced diabetic rats $(n=6)$.

Abbreviations: CA, Colocasia affinis; Gli, glibenclamide; HbAlc, glycated haemoglobin; STZ, streptozotocin.

\section{Effect of CA Leaves Extract on Kidney Profile}

Diabetic nephropathy is a common complication of diabetes. BUN and creatinine levels are widely used in the diagnosis of acute or chronic kidney diseases. ${ }^{30}$ We have evaluated the levels of serum creatinine and BUN to understand the plant extract's ability to decrease or normalize those kidney markers. Detail results of the study are illustrated in Figure 5. The CA leaves extract's oral administration significantly decreased both creatinine (Figure 5A) and BUN levels (Figure 5B) of the diabetic rats. In both cases, the higher dose $(500 \mathrm{mg} / \mathrm{kg})$ displayed better efficacy ( $\mathrm{p}$ $<0.00001)$ and was comparable with the standard drug glibenclamide.

\section{Effect of CA on Oxidative Stress and Antioxidant Enzymes}

We evaluated oxidative stress by determining nitric oxide (NO) and advanced oxidative protein products (AOPP) levels in the experimental rodents' liver and kidney homogenates. Our study demonstrated that oral administration of CA significantly decreased $\mathrm{NO}$ and AOPP levels in the diabetic rats. The efficacy of CA is better at $500 \mathrm{mg} / \mathrm{kg}$ dose to normalize the NO (p $<0.00001)$ in liver (Figure 6A) and NO $(\mathrm{p}<0.05)$ in kidney (Figure 6B). Similarly, CA showed higher effect at $500 \mathrm{mg} / \mathrm{kg}$ dose to regularize AOPP levels $(\mathrm{p}<0.00001)$ in liver (Figure 6C) and kidney $(\mathrm{p}<0.05)$ (Figure 6D), which were comparable with glibenclamide $(10 / \mathrm{mg} / \mathrm{kg})$ as represented in Figure 6. 

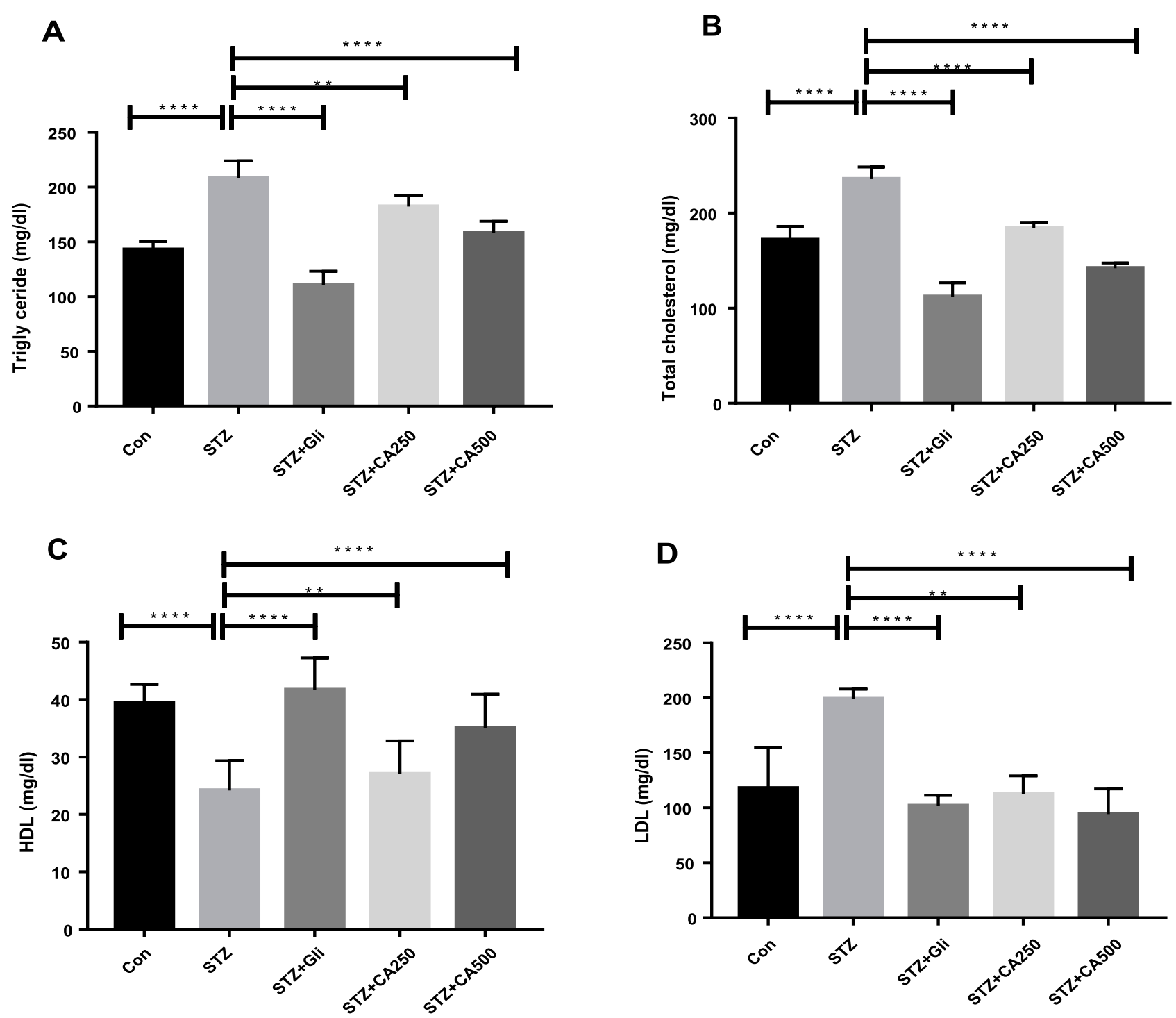

Figure 3 Effects of CA on lipid profile (A) triglyceride, (B) total cholesterol, (C) HDL, and (D) LDL in the diabetic rodents. Therapeutic efficacy of CA is compared with the antidiabetic drug glibenclamide. Data are expressed as means \pm S.E.M.; *****p $\leq 0.00001$ vs control or STZ; **p $\leq 0.001$ vs STZ-induced diabetic rats $(n=6)$.

Abbreviations: CA, Colocasia affinis; HDL, high-density lipoprotein; LDL, low-density lipoprotein; Gli, glibenclamide; STZ, streptozotocin.

We also estimated GSH and SOD levels, which are natural cellular antioxidants combating oxidative stress, to assess the plant extract's capacity to improve the experimental animals' hepatic impairment. STZ administration reduced GSH in liver $(\mathrm{p}<0.00001)$ and kidney $(\mathrm{p}<0.0001)$. STZ administration also decreased SOD levels in liver $(p<0.00001)$ and kidney $(p<0.05)$ in the experimental rats compared to the control animals. Further, oral gavage of CA dose-dependently improved GSH and SOD levels in the diabetic rats, as demonstrated in Figure 7, elucidating the CA leaves' effectiveness in ameliorating diabetes-induced hepatic and kidney impairment. In our experiments, a $500 \mathrm{mg} / \mathrm{kg}$ dose of CA exhibited better efficacy.

\section{Results of the Histological Evaluation of Liver and Kidney}

We performed H\&E staining to assess the antiinflammatory effects of $\mathrm{CA}$ in reducing inflammatory cell infiltration in the liver and kidney tissues of diabetic rats. Images of the control group (liver tissue) demonstrated normal hepatocytes with no inflammation Figure 8A. To the contrary, STZ-induced diabetic rats exhibited 
A

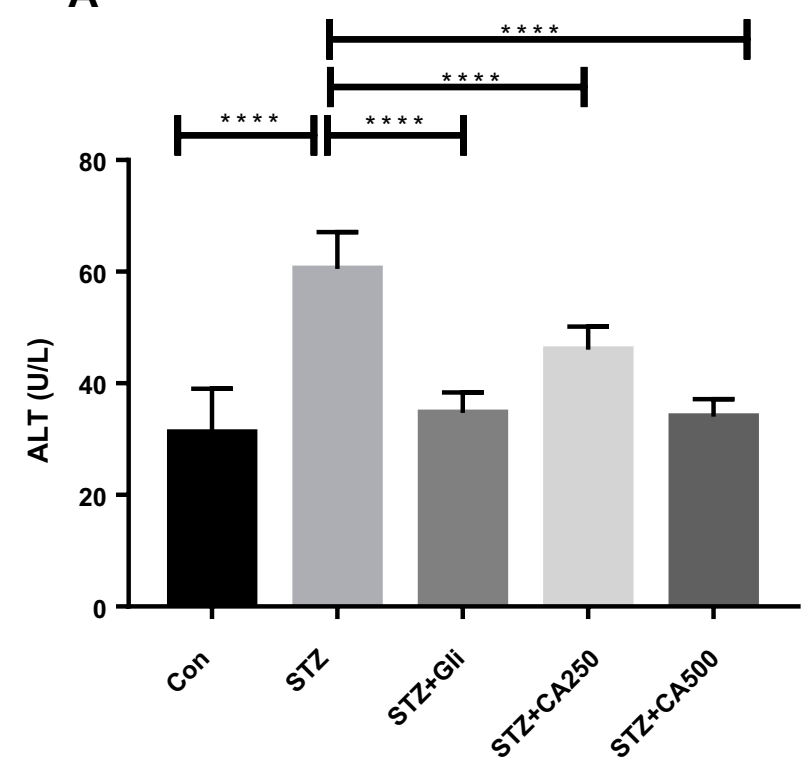

B

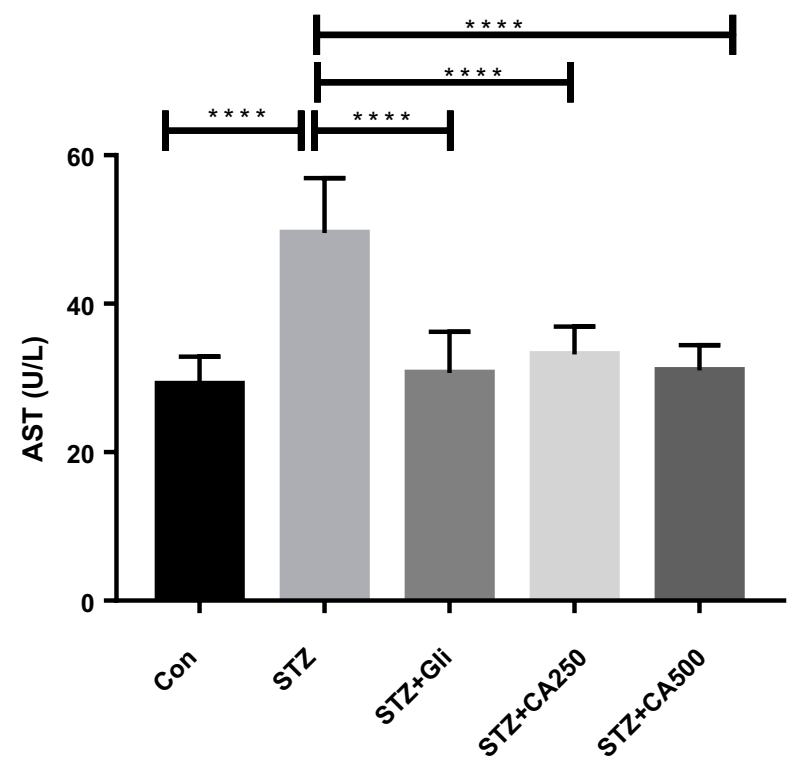

C

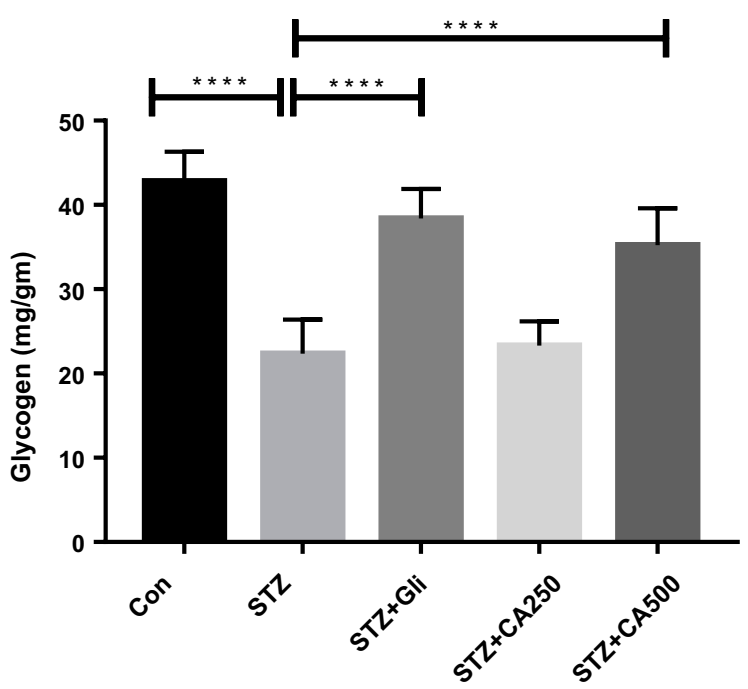

Figure 4 Efficacy of CA on liver functions (A) ALT, (B) AST, and (C) glycogen in the STZ-induced diabetic rats. Data are expressed as means \pm S.E.M.; $* * * *$ p $\leq 0.0000$ I vs control or STZ-induced diabetic rats $(n=6)$.

Abbreviations: CA, Colocasia affinis; ALT, alanine transaminase; AST, aspartate transaminase; Gli, glibenclamide; STZ, streptozotocin.

inflammatory cell infiltration (indicated by long arrows) (Figure 8B). Oral administration of $\mathrm{CA}$ ameliorated inflammatory cell migration (Figure $8 \mathrm{D}$ and $\mathrm{E}$ ). Apparently, our data elucidated effects of the CA leaves extract in mitigating hepatic inflammation.

Similarly, STZ-induced diabetic rats resulted in the significant sloughing of the cells of the proximal tubules (arrows head) and inflammatory cells migration (long arrows) (Figure 9B). Again, treatment with CA leaves extract improved the structures of proximal tubules and inflammation in the kidney. Details histology is shown in Figure 9.

\section{Potential Molecular Targets of CA Leaves} Extract

Our results demonstrated that $\mathrm{CA}$ and glibenclamide exerted comparable anti-inflammatory and antidiabetic properties in streptozotocin-induced diabetic rats. CA is 
A

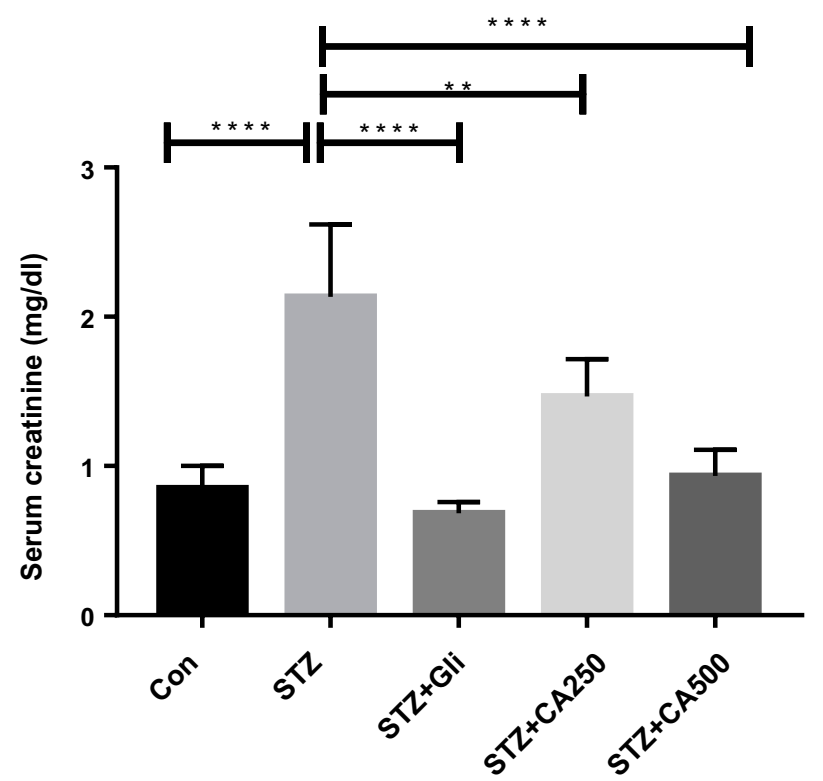

B

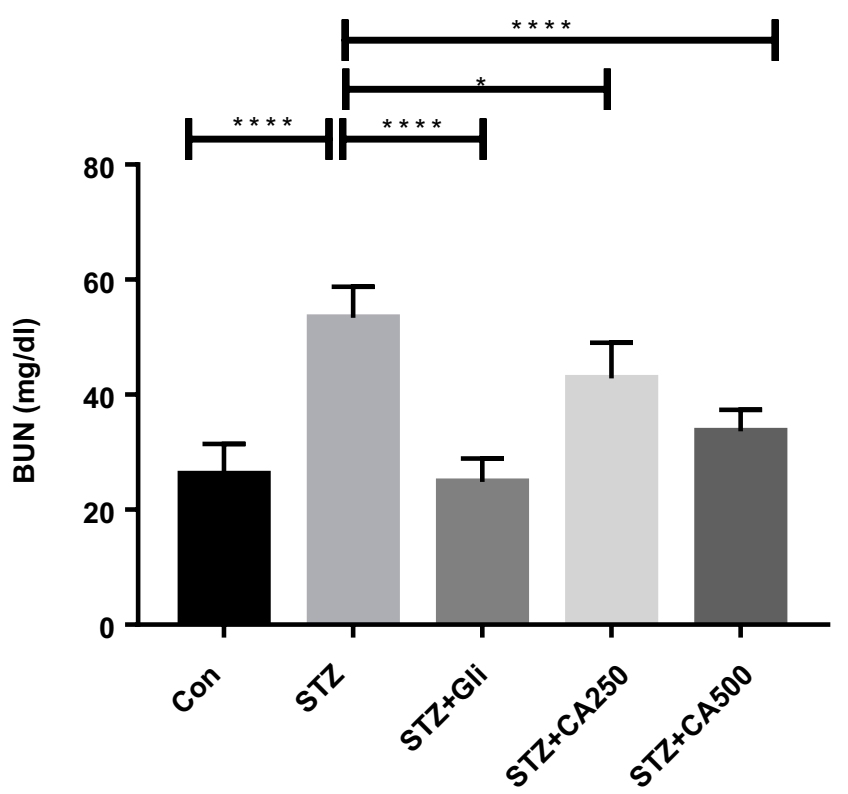

Figure 5 Effectiveness of CA leaves extract on kidney functions (A) serum creatinine and (B) BUN. Data are expressed as means \pm S.E.M.; $* * * * p \leq 0.0000$ I vs control or $\mathrm{STZ} ;{ }^{* *} \mathrm{p} \leq 0.00 \mathrm{I}$ vs STZ; * $\mathrm{p} \leq 0.05$ vs STZ -induced diabetic rats $(\mathrm{n}=6)$.

Abbreviations: CA, Colocasia affinis; BUN, blood urea nitrogen; Gli, glibenclamide; STZ, streptozotocin.

rich in polyphenolic compounds: kaempferol, myricetin, and rosmarinic acid. We performed rigid molecular docking of these compounds with various molecular targets of diabetes and inflammation using AutoDock. Estimated values of free energy of binding and inhibition constant are presented in Table 1. Glibenclamide (also known as glyburide) exerts hypoglycemia by closing ATP-sensitive potassium $\left(\mathrm{K}_{\mathrm{ATP}}\right)$ channels in pancreatic beta cells. ${ }^{31}$ The pore of the $\mathrm{K}_{\text {ATP }}$ channel is formed by Kir subunits (Kir6.1 or Kir6.2), which are surrounded by sulfonylurea receptors (SURs). ${ }^{32}$ The SUR1 protein has been co-crystallized with both glibenclamide ${ }^{33}$ and repaglinide. ${ }^{34}$ Molecular docking revealed binding of kaempferol, myricetin, and rosmarinic acid to the Kir6.2 subunit of SUR1 with a binding energy of $-6.3 \mathrm{kcal} / \mathrm{mol},-6.1 \mathrm{kcal} / \mathrm{mol}$, and $-7.05 \mathrm{kcal} /$ mol, respectively (Table 1 and Figure 10A-D). Glibenclamide binding site of SUR1 involves ARG306, TRP4360, ASN437, THR1242, ASN1245, and ARG1246. ${ }^{35}$ All three polyphenols of CA showed interactions with ASN1245 and ARG1246 in docked complexes (Figure 10A-D). Interestingly, rosmarinic acid showed hydrogen bonding with two additional critical binding residues, TYR377 and ARG1300, and exhibited the lowest estimated inhibition constant $(6.79 \mu \mathrm{M})$ (Table 1, Figure 10D) among three phytoconstituents.

Peroxisome proliferator-activated receptor- $\gamma$ (PPARgamma) is another target of antidiabetic agents. We performed docking analysis with a crystal structure of PPAR-gamma bound to pioglitazone (PDB ID: 2XKW) (Figure 10E-H). Myricetin showed a binding energy of $-7.08 \mathrm{kcal} / \mathrm{mol}$ and an inhibition constant of $14.64 \mu \mathrm{M}$ (Table 1). Protein-ligand interaction map indicated that myricetin could form four hydrogen bonds with three residues, ILE281, GLU291, and LEU340, of PPARgamma (Figure 10G). Inhibitors of dipeptidyl peptidase-4 (DPP-4), such as sitagliptin and vildagliptin, are widely used for the treatment of T2DM. ${ }^{36,37}$ Kaempferol, myricetin, and rosmarinic acid also showed favorable protein-ligand interactions with DPP4 (PDB ID: 6B1E) (Figure 10I-L).

Complex interplay exists between diabetes and inflammation and inhibition of SUR1, DPP4, and PPAR-gamma is also known to attenuate inflammatory responses. ${ }^{38,39}$ Our in vivo study also demonstrated considerable antiinflammatory properties of both $\mathrm{CA}$ and glibenclamide. Intriguingly, glibenclamide showed in vitro binding to 
A

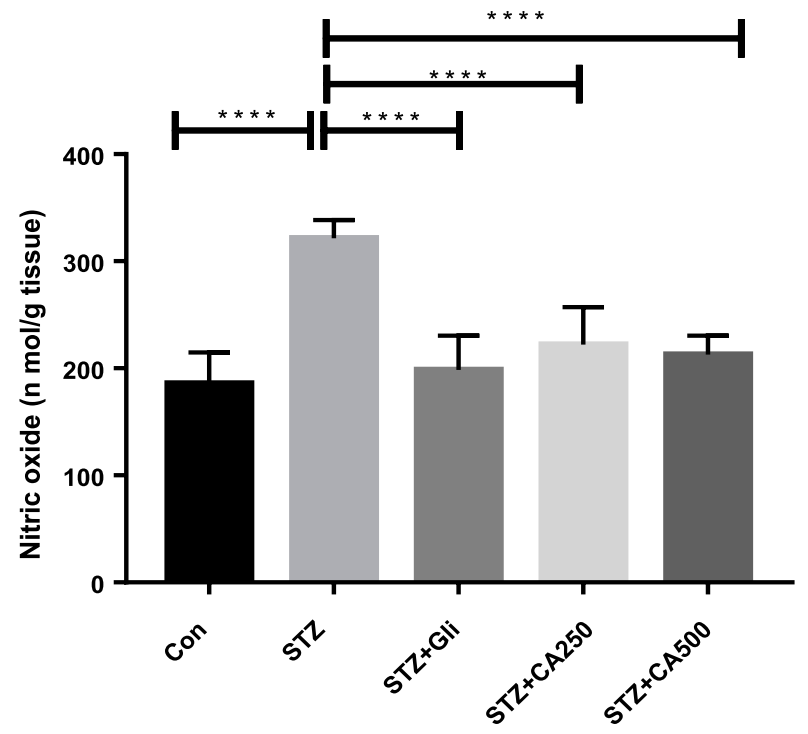

C

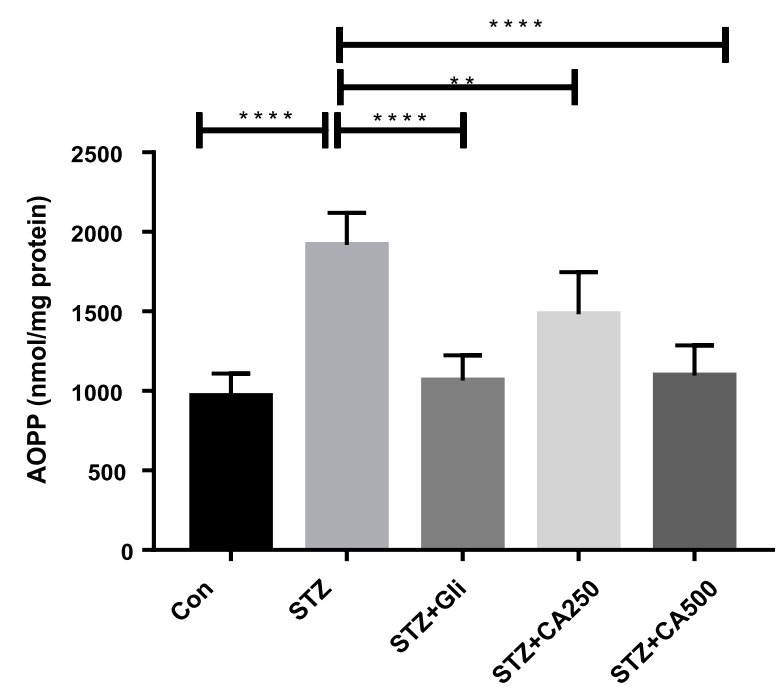

B

Kidney
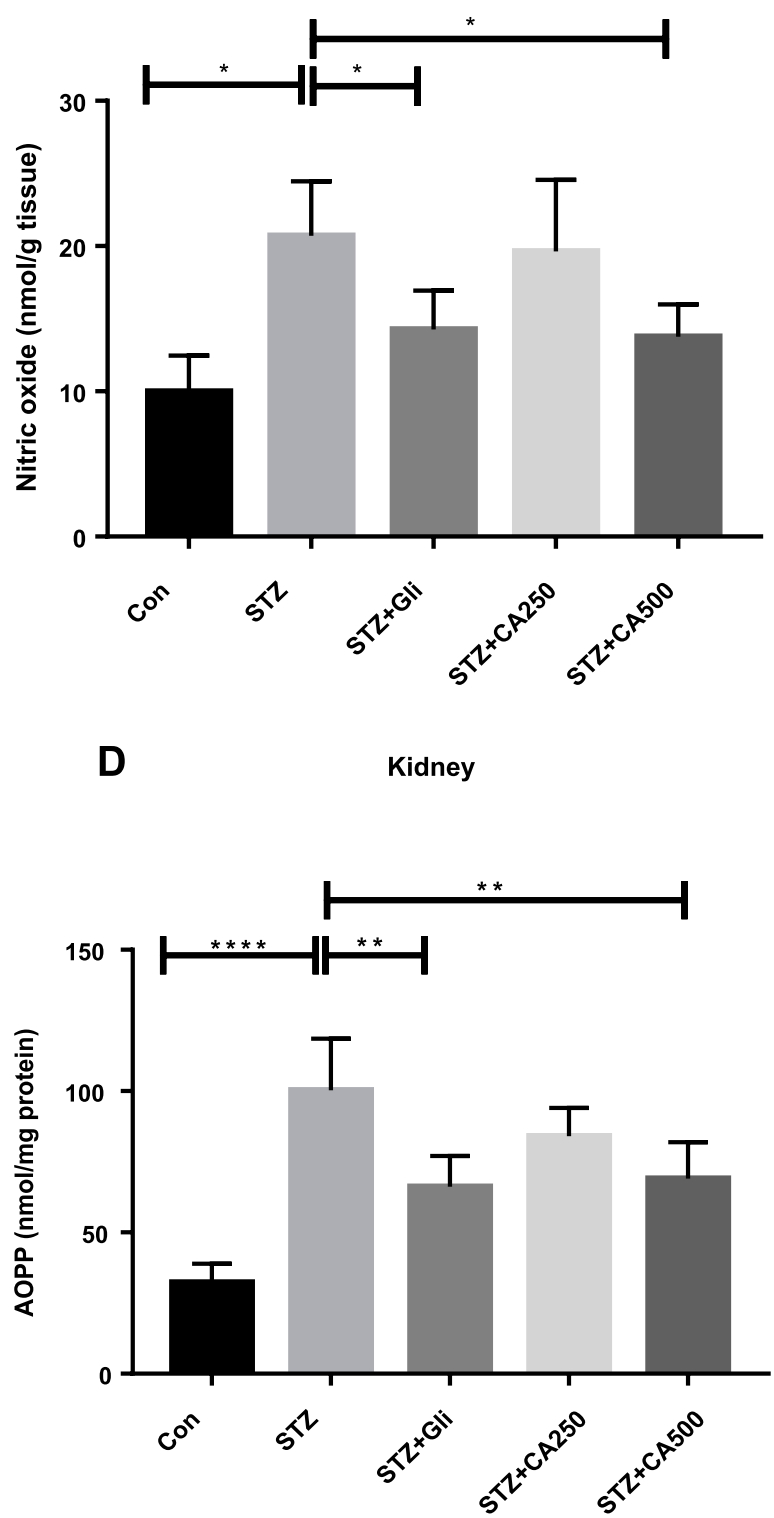

Figure 6 Effect of CA on oxidative stress (A) nitric oxide (liver) (B) nitric oxide (kidney) (C) AOPP (liver) (D) AOPP (kidney). Data are expressed as means \pm S.E.M.; ***** $\leq 0.0000$ I vs control or STZ; **p $\leq 0.001$ vs STZ; *p $\leq 0.05$ vs STZ-induced diabetic rats $(n=3-6)$.

Abbreviations: CA, Colocasia affinis; AOPP, advanced oxidation protein products; GSH, glutathione; SOD, superoxide dismutase, Gli, glibenclamide; STZ, streptozotocin.

aldo-keto reductase family1C member 3 (AKR1C3), ${ }^{40}$ a potential target for nonsteroidal anti-inflammatory drugs. Molecular docking analysis showed relatively stronger binding of the polyphenols, particularly rosmarinic acid, to AKR1C3. Rosmarinic acid showed a binding energy of $-8.66 \mathrm{kcal} / \mathrm{mol}$ and an inhibition constant of $451.37 \mathrm{nM}$ for AKR1C3 (Table 1). We next studied whether the kaempferol, myricetin, and rosmarinic acid could bind in silico to conventional molecular targets for inflammation. Among these three polyphenols, rosmarinic acid was docked to COX-2 with the lowest estimated free energy of binding $(-7.3 \mathrm{kcal} / \mathrm{mol})$ (Table 1, Figure 11AD). On the other hand, both kaempferol and myricetin showed stronger binding to interleukin-1 receptor type 1 (IL1R1) with binding energy values of $-7.84 \mathrm{kcal} / \mathrm{mol}$ and $-7.85 \mathrm{kcal} / \mathrm{mol}$, respectively (Table 1 ). It is noteworthy 
A

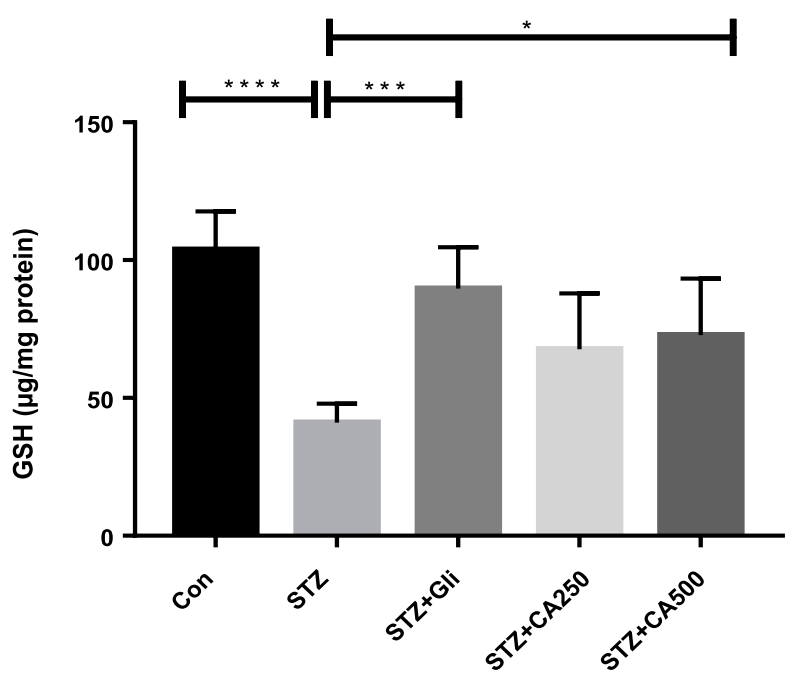

C

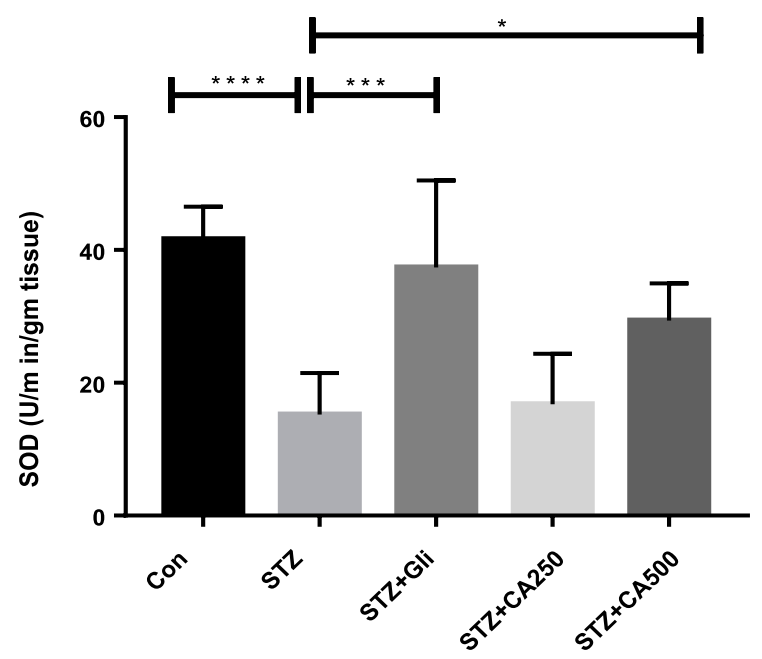

B Kidney

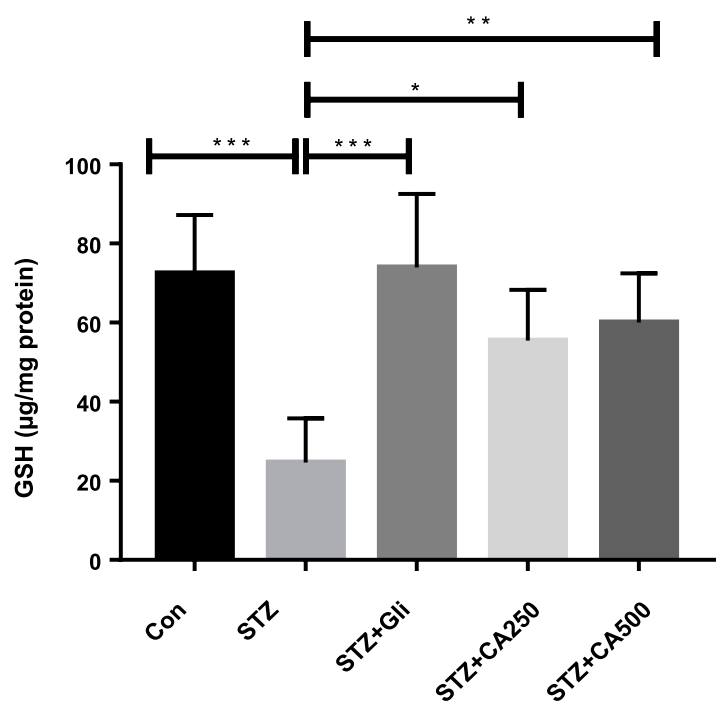

D

Kidney

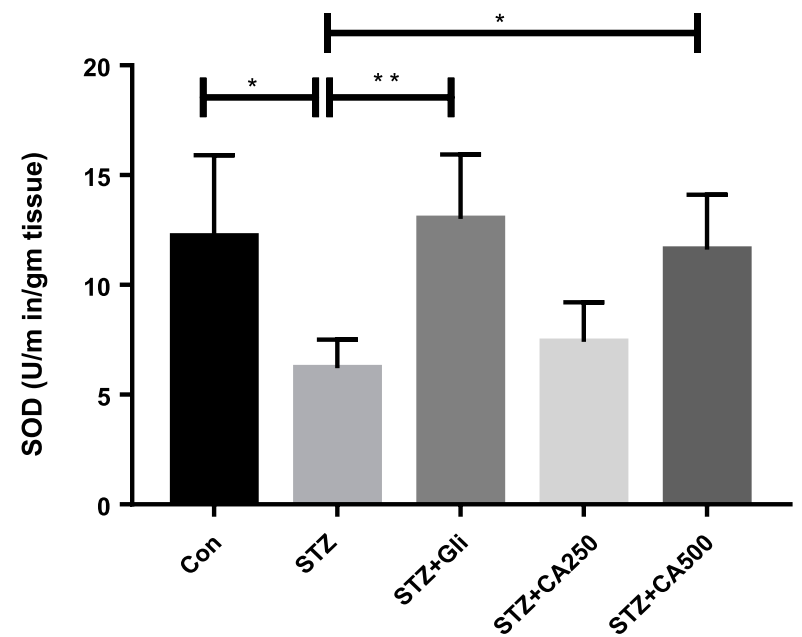

Figure 7 Effect of CA on antioxidant enzymes (A) GSH (liver), (B) GSH (kidney) (C) SOD (liver), (D) SOD (kidney). Data are expressed as means \pm S.E.M.; ***** $\leq$ 0.00001 vs control or STZ; ***p $\leq 0.0001$ vs STZ; **p $\leq 0.001$ vs STZ; *p $\leq 0.05$ vs STZ -induced diabetic rats $(n=3-6)$.

Abbreviations: CA, Colocasia affinis; AOPP, advanced oxidation protein products; GSH, glutathione; SOD, superoxide dismutase, Gli, glibenclamide; STZ, streptozotocin.

that the binding sites were slightly different for these two compounds (Figure 11E-H). Nevertheless, both showed formation of multiple hydrogen bonds with IL1R1 (Figure $11 \mathrm{~F}$ and $\mathrm{G})$. Tumor necrosis factor- $\alpha$ (TNFalpha) is a pro-inflammatory cytokine and a masterregulator of inflammatory responses, ${ }^{41}$ and hypoglycemic drugs can modulate TNF-alpha signalling, possibly through inhibition of PPAR-gamma. ${ }^{42,43}$ All three constituents of CA clustered at a similar binding region of TNF-alpha and exhibited moderate binding affinities in our docking analysis (Table 1, Figure 11I-L).

Together, our in silico docking and protein-ligand interaction analyses support the idea that CA's major constituents can bind to conventional molecular targets of both diabetes and inflammation, and can explain, at least in part, the in vivo medicinal properties of CA. 


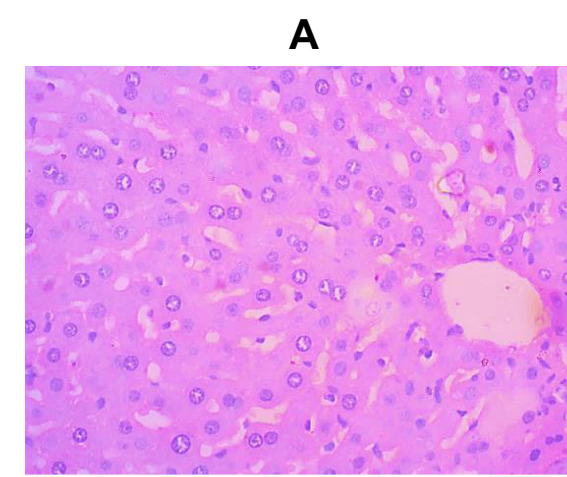

Control
B

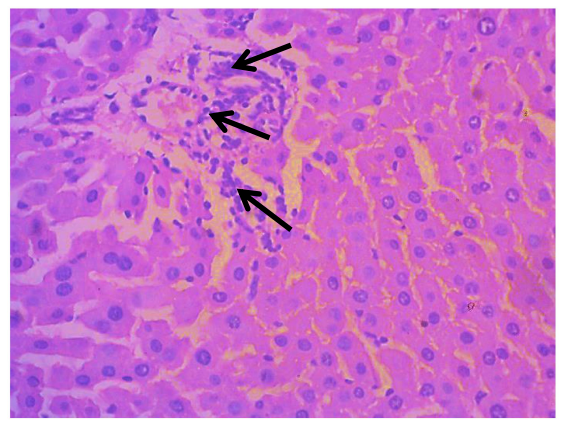

STZ

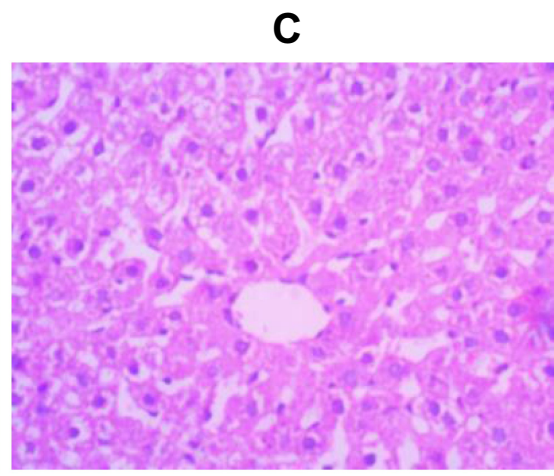

STZ+CA 250 mg/kg
D

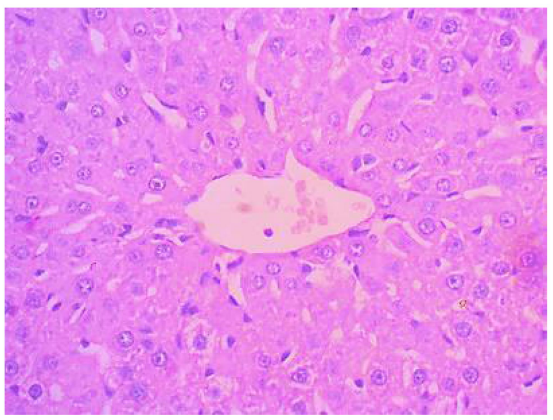

STZ+CA 500 mg/kg
E

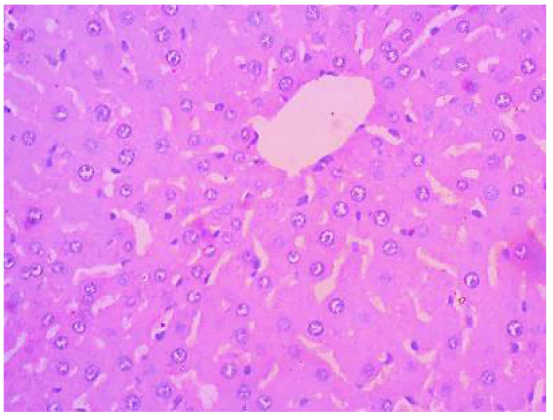

STZ+ GLI

Figure 8 Histological evaluation of liver after treatment with CA. (A) Hepatocytes of control animals. (B) Inflammatory cells infiltration after STZ-induced diabetes. Hepatocytes of animals treated with CA leave extracts (C, D) and glibenclamide (E).

Abbreviations: CA, Colocasia affinis; Gli, glibenclamide.

\section{Discussion}

Diabetes is one of the critical health complications, and its prevalence and associated health disorders are rising globally, particularly in South Asia. World Health Organization (WHO) also assessed the rising health problems associated with diabetes in Bangladesh. ${ }^{1-3}$ Diabetes is characterized by a series of abnormalities such as elevated blood glucose levels and $\mathrm{HbAlc}$, insulin resistance, irregular lipid profile, hepatic impairment, renal disorders, loss of body weight, escalation in inflammation, and oxidative stress, and reduction in antioxidants activities. ${ }^{4-10}$

In the present study, intraperitoneal STZ injections decreased the body weight and increased blood glucose and $\mathrm{HbA1c}$ levels in the experimental rats compared to the control rats. The oral administration of CA for 28 days significantly increased body weight (Figure 2), decreased serum glucose and HbA1c levels (Figure 1) in the experimental animals. Our results were very similar to previous studies $^{4,6,8,44,45}$ for the management of diabetes. In diabetes, hyperglycemia and insulin resistance are correlated with lipid abnormalities. Therefore, therapeutics that could modify lipid profiles are worthy candidates for the management of diabetic complications. ${ }^{5,10,29,45}$ In the present study, oral gavage of CA leaves extract at a $500 \mathrm{mg} / \mathrm{kg}$ dose significantly attenuated the TG, TC, and LDL cholesterol levels and elevated HDL levels in diabetic rats. These data are consistent with the former studies. ${ }^{9} 16,28,29,45$

The liver maintains glucose homeostasis through a series of events, including gluconeogenesis, glycogenolysis, glycogen synthesis, and glycolysis. However, these biochemical processes are interrupted in diabetes leading to hyperglycemia. ${ }^{10}$ Hepatic AST, ALT, and ALP enzymes are common markers of liver function. ${ }^{46}$ An upsurge in hepatic AST and ALT activities in diabetes results from defective glucose utilization and indicates hepatic dysfunctions. Accordingly, a high level of ALT and AST are markers of diabetic pathogenesis. ${ }^{47}$ Again, STZ-induced diabetes exhibits pancreatic beta-cell destruction and depletion of hepatic glycogen levels followed by insulin resistance and hindered glycogen synthesis. ${ }^{48,49}$ In the present study, intraperitoneal injection of STZ significantly 
A

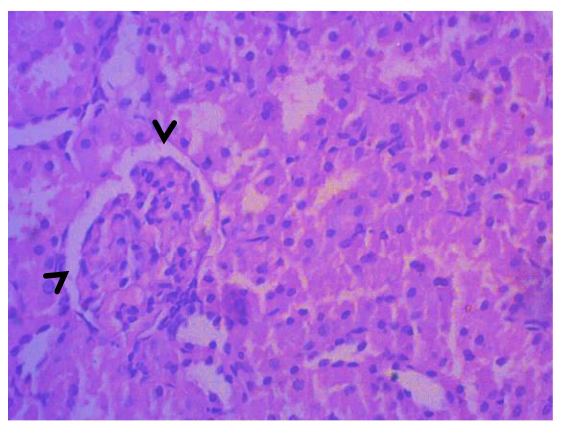

Control
B

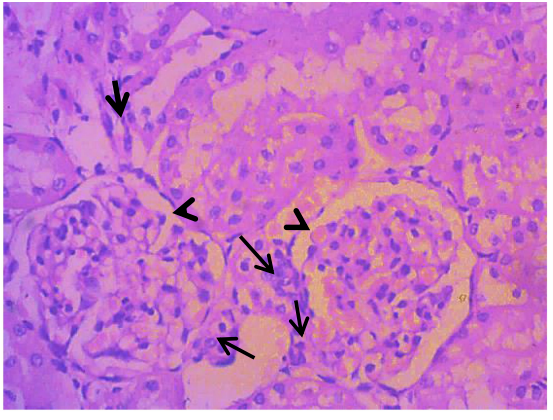

STZ

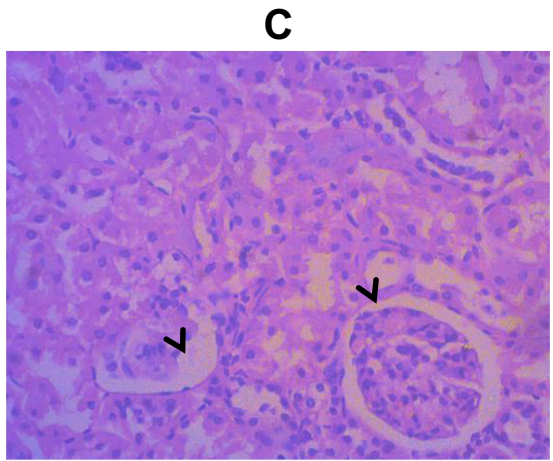

STZ+CA $250 \mathrm{mg} / \mathrm{kg}$
D

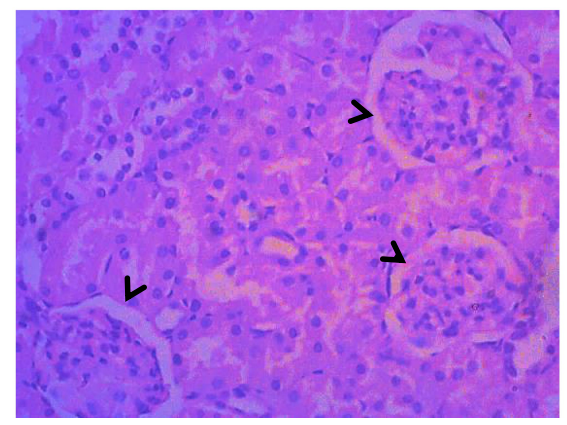

STZ+CA $500 \mathrm{mg} / \mathrm{kg}$

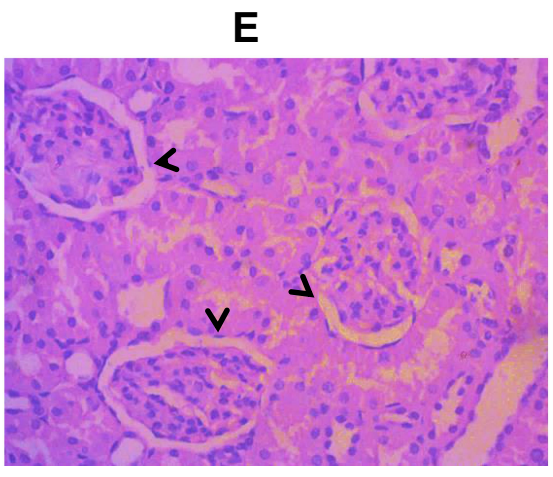

STZ+GLI

Figure 9 Histological evaluation of diabetic kidney after treatment with CA. (A) Kidney tissues of control animals. (B) sloughing of the cells of the proximal tubules in kidney after STZ-induced diabetes. Architecture of kidney tissues treated with CA leaves extracts (C, D) and glibenclamide (E).

Abbreviations: CA, Colocasia affinis; Gli, glibenclamide.

increased serum ALT and AST and decreased liver glycogen levels in diabetic rats compared to that of the control rats. Interestingly, oral treatment with CA leaves extract at $250 \mathrm{mg} / \mathrm{kg}$ and $500 \mathrm{mg} / \mathrm{kg}$ significantly lowered these hepatic enzymes' levels, suggesting that CA leaves extract may protect the liver tissue impairment caused by STZinduced diabetes.

Moreover, treatment with CA leaves extract at $500 \mathrm{mg} /$ $\mathrm{kg}$ resulted in a significant increase in liver glycogen (Figure 4C). These results are very similar to the previous works. ${ }^{9,16,29,48,49}$ Diabetes is also associated with kidney diseases and BUN and creatinine are used as the initial investigative tools to detect renal impairments. ${ }^{30,50}$ Our study demonstrated that oral administration of CA leaves extract significantly ameliorated serum creatinine and BUN levels in experimental rats, which was similar to that of glibenclamide, indicating the plant's profound therapeutic effectiveness in diabetic nephropathy.

Previous data showed that administration of STZ in experimental animals elevated plasma nitric oxide (NO) levels, which resulted in pancreatic beta-cell apoptosis. ${ }^{51}$ Glucotoxicity and oxidative stress are correlated and are known to cause liver pathogenicity in diabetes. ${ }^{52}$ Earlier studies showed that increased production of advanced oxidation protein products (AOPPs) and oxidative stress in diabetes was associated with micro-/macrovascular and hepatic complications. ${ }^{53,54}$ The present work demonstrated a significant increase in both NO and AOPP levels in the STZ-induced diabetic animals than the control rats. Treatment with CA leaves extracts normalized it. Furthermore, GSH and SOD are two natural antioxidants involved in free radicals scavenging. Previous reports demonstrated organ damage due to the diminished levels of GSH and SOD in the STZ-induced diabetic rodents. ${ }^{55,56}$ Our study revealed that treatment with CA leaves extract significantly increased the level of antioxidant enzymes GSH and SOD, which is a clear indication of CA's therapeutic potential for managing diabetes-induced hepatic complications. 


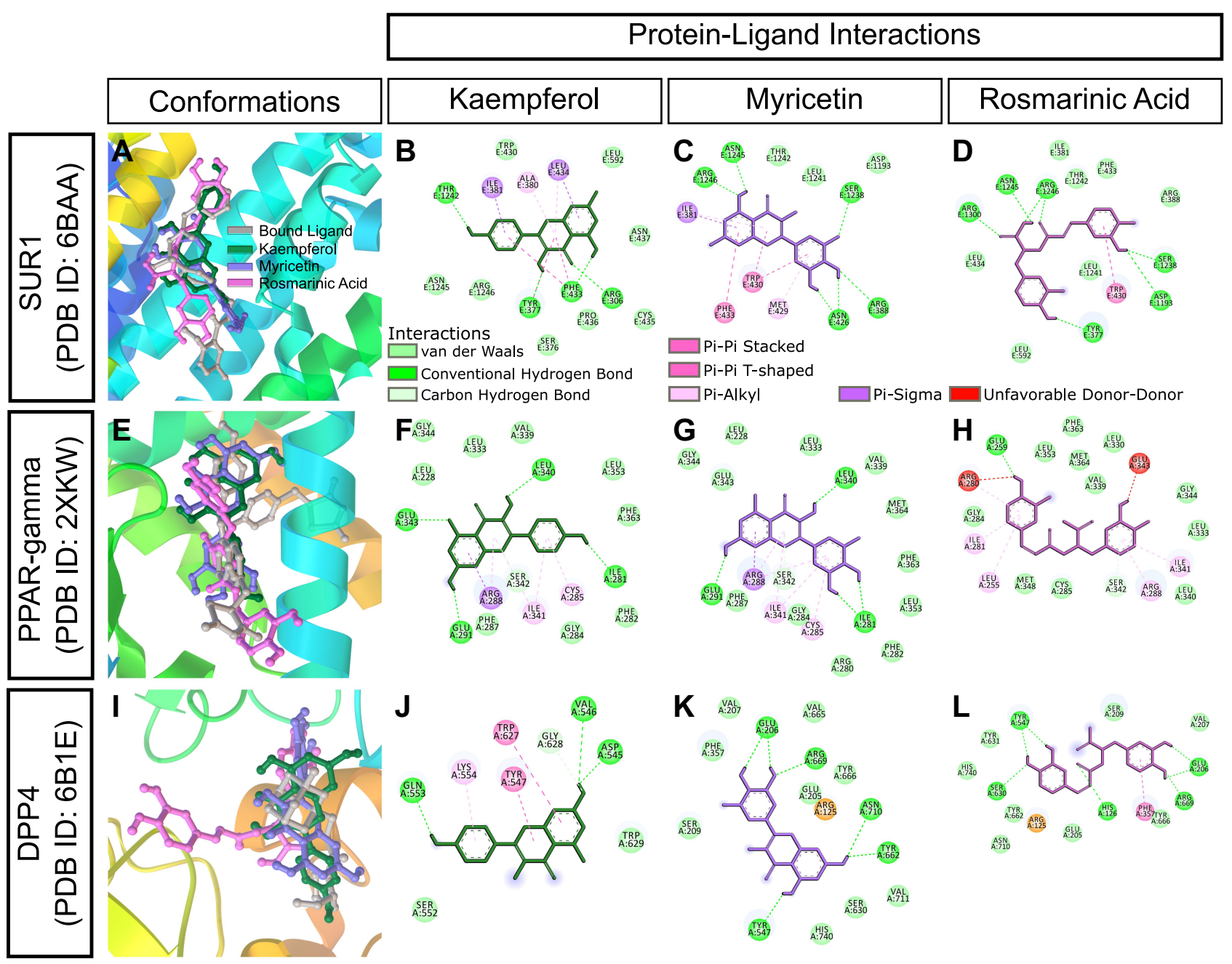

Figure 10 In silico binding of kaempferol, myricetin and rosmarinic acid to molecular targets of diabetes. (A-D) SURI, (E-H) PPAR-gamma, and (I-L) DPP4 complexes with ligands. Protein secondary structures are shown as depth-cued cartoons (rainbow) and ligands are shown as sticks. The leftmost columns show best docking poses and other columns depict 2-D representations of protein-ligand interactions.

Previous studies demonstrated correlations of the overproduction of NO, AOPP, and diminished levels of antioxidant enzymes GSH, SOD with structural abnormalities of the vital organs such as the liver and the kidney in STZinduced diabetic animals. ${ }^{51-56}$ The present work also showed inflammation and damage of liver and kidney tissues in diabetic rats. Simultaneously, treatment with CA leaves extracts compensated the mutilation, possibly by the scavenging of oxidative destruction.

Previously, we characterized the phytoconstituents in CA leaves using HPLC. ${ }^{13}$ Our data revealed that the leaves of the plant are rich in polyphenolic compounds kaempferol and myricetin. It also contains rosmarinic acid, p-coumaric acid, and trans-ferulic acid. ${ }^{13}$ Kaempferol is recognized as a potent antidiabetic compound that can suppress hepatic glucose production and oxidative stress. ${ }^{57,58}$ It also possesses significant anti-inflammatory and antioxidant properties. ${ }^{59}$ Earlier evidence also demonstrated antidiabetic and organ protective effects of myricetin and rosmarinic acid. ${ }^{60-62}$ Our data demonstrated hepato- and reno-protective effects and normalization of biochemical and histopathological markers by the CA leaves extract in STZ-induced diabetic rats. In silico studies also exhibited inhibition of diabetic and inflammatory mediators involved in the disease pathogenesis by the major phytoconstituents of CA. Overall, our data suggest significant therapeutic potentials of the leaves extract of $\mathrm{CA}$ in managing diabetic complications.

\section{Conclusion}

The present study demonstrated profound antidiabetic effects of the ethanolic extract of leaves of CA by ameliorating plasma glucose and $\mathrm{HbA1c}$ in STZinduced diabetic rats. The extract also showed notable 


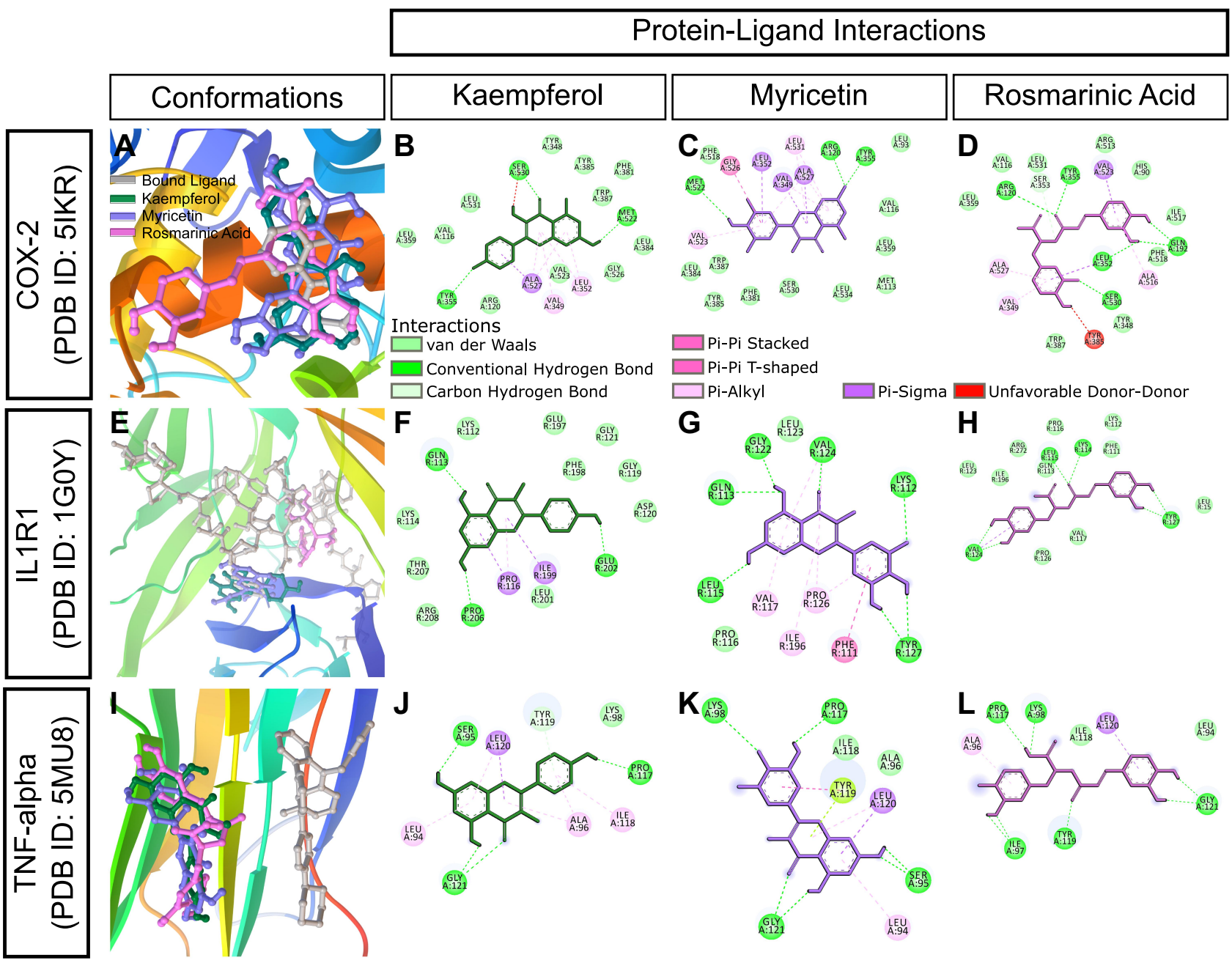

Figure II In silico binding of kaempferol, myricetin and rosmarinic acid to molecular targets of inflammation. (A-D) COX-2, (E-H) ILIRI, and (I-L) TNF-alpha complexes with ligands. Protein secondary structures are shown as depth-cued cartoons (rainbow) and ligands are shown as sticks. The leftmost columns show best docking poses and other columns depict 2-D representations of protein-ligand interactions.

antidyslipidemic, hepatoprotective, and renoprotective effects. These findings will help natural product scientists to isolate bioactive compounds from the plant and thus contribute to the drug discovery of new entities to manage non-communicable diseases.

\section{Acknowledgments}

The authors are grateful to Ministry of Science and Technology (Ref: 39.00.0000.012.002.05.19- S1. No. 126), The People's Republic of Bangladesh for funding this study under R\&D 2019-2020.

\section{Author Contributions}

All authors made a significant contribution to the work reported, whether that is in the conception, study design, execution, acquisition of data, analysis, and interpretation, or in all these areas; took part in drafting, revising or critically reviewing the article; gave final approval of the version to be published; have agreed on the journal to which the article has been submitted; and agree to be accountable for all aspects of the work.

\section{Disclosure}

The authors declare no financial or non-financial conflicts of interest for this work.

\section{References}

1. Danaei G, Finucane MM, Lu Y, et al. National, regional, and global trends in fasting plasma glucose and diabetes prevalence since 1980: systematic analysis of health examination surveys and epidemiological studies with 370 country-years and 2.7 million participants. Lancet. 2011;378(9785):31-40. doi:10.1016/S0140-6736(11) 60679-X 
2. Mendis S, Puska P, Norrving B, Organization WH, Federation WH, Organization WS. Global Atlas Cardiovascular Disease Prevention and Control. World Health Organization; 2011. https://apps.who.int/ iris/handle/10665/44701. Accessed November 9, 2020.

3. MdR I, Arslan I, Attia J, et al. Is Serum Zinc Level Associated with Prediabetes and Diabetes?: a Cross-Sectional Study from Bangladesh. Song Y, ed. PLoS One. 2013;8(4):e61776. doi:10.1371/journal. pone. 0061776

4. Koenig RJ, Peterson CM, Jones RL, Saudek C, Lehrman M, Cerami A. Correlation of glucose regulation and hemoglobin AIc in diabetes mellitus. $N$ Engl J Med. 1976;295(8):417-420. doi:10.1056/ NEJM197608192950804

5. Clark JM, Diehl AM. Hepatic steatosis and type 2 diabetes mellitus. Curr Diab Rep. 2002;2(3):210-215. doi:10.1007/s11892-002-0085-3

6. Rajasekaran S, Sivagnanam K, Subramanian S. Antioxidant effect of Aloe vera gel extract in streptozotocin-induced diabetes in rats. Pharmacol Rep. 2005;57(1):90-96.

7. Hotamisligil GS. Inflammation and metabolic disorders. Nature. 2006;444(7121):860-867. doi:10.1038/nature05485

8. Abdelmeguid NE, Fakhoury R, Kamal SM, Al Wafai RJ. Effects of Nigella sativa and thymoquinone on biochemical and subcellular changes in pancreatic $\beta$-cells of streptozotocin-induced diabetic rats. $J \quad$ Diabetes. 2010;2(4):256-266. doi:10.1111/j.17530407.2010.00091.x

9. Pandhare RB, Sangameswaran B, Mohite PB, Khanage SG. Antihyperglycaemic and lipid lowering potential of Adenanthera pavonina Linn. in streptozotocin induced diabetic rats. Orient Pharm Exp Med. 2012;12(3):197-203. doi:10.1007/s13596-012-0074-2

10. Petersen MC, Vatner DF, Shulman GI. Regulation of hepatic glucose metabolism in health and disease. Nat Rev Endocrinol. 2017;13 (10):572-587. doi:10.1038/nrendo.2017.80

11. Lenzen S. The mechanisms of alloxan- and streptozotocin-induced diabetes. Diabetologia. 2008;51(2):216-226. doi:10.1007/s00125007-0886-7

12. Fabricant DS, Farnsworth NR. The value of plants used in traditional medicine for drug discovery. Environ Health Perspect. 2001;109 (Suppl 1):69-75. doi:10.1289/ehp.01109s169

13. Dev S, Acharyya RN, Shill MC, et al. Bioactivities of Colocasia affinis Schott and profiling of its bioactive polyphenols by HPLC-DAD. Bangladesh Pharm J. 2021;24(1):1-10

14. Mondal M, Hossain MS, Das N, et al. Phytochemical screening and evaluation of pharmacological activity of leaf Methanolic extract of Colocasia affinis Schott. Clin Phytosci. 2019;5(1):8. doi:10.1186/ s40816-019-0100-8

15. Choudhury H, Pandey M, Hua CK, et al. An update on natural compounds in the remedy of diabetes mellitus: a systematic review. J Tradit Complement Med. 2017;8(3):361-376. doi:10.1016/j. jtcme.2017.08.012

16. Hannan JMA, Ali L, Rokeya B, et al. Soluble dietary fibre fraction of Trigonella foenum-graecum (fenugreek) seed improves glucose homeostasis in animal models of type 1 and type 2 diabetes by delaying carbohydrate digestion and absorption, and enhancing insulin action. $B r \quad J$ Nutrition. 2007;97(3):514-521. doi:10.1017/ S0007114507657869

17. Peirce S, Clinical AEC SOP 26 Euthanasia of laboratory-animals; 2013. Available from: https://www.svhm.org.au/ArticleDocuments/ 1938/AEC-Clinical-SOP-26-Euthanasia-of-laboratory-animals.pdf. aspx?embed=y. Accessed November 9, 2020

18. Seifter S, Dayton S, Novic B, Muntwyler E. The estimation of glycogen with the anthrone reagent. Arch Biochem. 1950;25:191-200.

19. Tracey WR, Tse J, Carter G. Lipopolysaccharide-induced changes in plasma nitrite and nitrate concentrations in rats and mice: pharmacological evaluation of nitric oxide synthase inhibitors. J Pharmacol Exp Ther. 1995;272(3):1011-1015.
20. Witko-Sarsat V, Friedlander M, Capeillère-Blandin $C$, et al. Advanced oxidation protein products as a novel marker of oxidative stress in uremia. Kidney Int. 1996;49(5):1304-1313. doi:10.1038/ ki.1996.186

21. Lamia SS, Emran T, Rikta JK, et al. Coenzyme Q10 and Silymarin Reduce CCl4-Induced Oxidative Stress and Liver and Kidney Injury in Ovariectomized Rats-Implications for Protective Therapy in Chronic Liver and Kidney Diseases. Pathophysiology. 2021;28 (1):50-63. doi:10.3390/pathophysiology28010005

22. Misra HP, Fridovich I. The role of superoxide anion in the autoxidation of epinephrine and a simple assay for superoxide dismutase. $J$ Biol Chem. 1972;247(10):3170-3175. doi:10.1016/S00219258(19)45228-9

23. Jollow DJ, Mitchell JR, Zampaglione N, Gillette JR. Bromobenzeneinduced liver necrosis. Protective role of glutathione and evidence for 3,4-bromobenzene oxide as the hepatotoxic metabolite. Pharmacology. 1974;11(3):151-169. doi:10.1159/000136485

24. O’Boyle NM, Banck M, James CA, Morley C, Vandermeersch T, Hutchison GR. Open Babel: an open chemical toolbox. J Cheminform. 2011;3(1):33. doi:10.1186/1758-2946-3-33

25. Samdani A, Vetrivel U. POAP: a GNU parallel based multithreaded pipeline of open babel and AutoDock suite for boosted high throughput virtual screening. Comput Biol Chem. 2018;74:39-48. doi:10.1016/j.compbiolchem.2018.02.012

26. Morris GM, Huey R, Lindstrom W, et al. AutoDock4 and AutoDockTools4: automated Docking with Selective Receptor Flexibility. J Comput Chem. 2009;30(16):2785-2791. doi:10.1002/ jcc. 21256

27. Andallu B, Vinay Kumar AV, Varadacharyulu NC. Lipid abnormalities in streptozotocin-diabetes: amelioration by Morus indica L. cv Suguna leaves. Int J Diabetes Dev Ctries. 2009;29(3):123-128. doi:10.4103/0973-3930.54289

28. Almeida DAT, Braga CP, Novelli ELB, Fernandes AAH. Evaluation of lipid profile and oxidative stress in STZ-induced rats treated with antioxidant vitamin. Braz Arch Biol Tech. 2012;55(4):527-536. doi:10.1590/S1516-89132012000400007

29. Yadav KS, Yadav NP, Shanker K, et al. Assessment of antidiabetic potential of Cissampelos pareira leaf extract in streptozotocin-nicotinamide induced diabetic mice. J Pharm Res. 2013;6(8):874-878. doi:10.1016/j.jopr.2013.06.027

30. Dabla PK. Renal function in diabetic nephropathy. World J Diabetes. 2010;1(2):48-56. doi:10.4239/wjd.v1.i2.48

31. Gribble FM, Reimann F. Sulphonylurea action revisited: the post-cloning era. Diabetologia. 2003;46(7):875-891. doi:10.1007/ s00125-003-1143-3

32. Quan Y, Barszczyk A, Feng Z, Sun H. Current understanding of $\mathrm{K}$ ATP channels in neonatal diseases: focus on insulin secretion disorders. Acta Pharmacol Sin. 2011;32(6):765-780. doi:10.1038/ aps. 2011.57

33. Martin GM, Sung MW, Yang Z, et al. Mechanism of pharmacochaperoning in a mammalian KATP channel revealed by cryo-EM. eLife. 2019;8:e46417. doi:10.7554/eLife.46417

34. Ding D, Wang M, Wu J-X, Kang Y, Chen L. The structural basis for the binding of repaglinide to the pancreatic KATP Channel. Cell Rep. 2019;27(6):1848-1857.e4. doi:10.1016/j.celrep.2019.04.050

35. Martin GM, Kandasamy B, DiMaio F, Yoshioka C, Shyng S-L. Antidiabetic drug binding site in a mammalian KATP channel revealed by Cryo-EM. Swartz KJ, ed. eLife. 2017;6:e31054. doi:10.7554/ eLife.31054

36. Richter B, Bandeira-Echtler E, Bergerhoff K, Lerch C. Dipeptidyl peptidase-4 (DPP-4) inhibitors for type 2 diabetes mellitus. Cochrane Database Sys Rev. 2008;2. doi:10.1002/14651858.CD006739.pub2

37. Baetta R, Corsini A. Pharmacology of Dipeptidyl Peptidase-4 Inhibitors. Drugs. 2011;71(11):1441-1467. doi:10.2165/11591400000000000-00000 
38. Simard JM, Geng Z, Woo SK, et al. Glibenclamide reduces inflammation, vasogenic edema, and caspase-3 activation after subarachnoid hemorrhage. J Cereb Blood Flow Metab. 2009;29(2):317-330. doi:10.1038/jcbfm.2008.120

39. Kothari V, Galdo JA, Mathews ST. Hypoglycemic agents and potential anti-inflammatory activity. $J$ Inflamm Res. 2016;9:27-38. doi:10.2147/JIR.S86917

40. Zhao Y, Zheng X, Zhang $\mathrm{H}$, et al. In vitro inhibition of AKR1Cs by sulphonylureas and the structural basis. Chem Biol Interact. 2015;240:310-315. doi:10.1016/j.cbi.2015.09.006

41. Zelová H, Hošek JTNF. $\alpha$ signalling and inflammation: interactions between old acquaintances. Inflamm Res. 2013;62(7):641-651. doi:10.1007/s00011-013-0633-0

42. Peraldi $\mathrm{P}, \mathrm{Xu}$ M, Spiegelman BM. Thiazolidinediones block tumor necrosis factor-alpha-induced inhibition of insulin signaling. $J$ Clin Invest. 1997;100(7):1863-1869. doi:10.1172/JCI119715

43. Fukuzawa M, Satoh J, Qiang X, et al. Inhibition of tumor necrosis factor- $\alpha$ with anti-diabetic agents. Diabetes Res Clin Pract. 1999;43 (3):147-154. doi:10.1016/S0168-8227(99)00005-4

44. Mohal S, Mondal DK, Shamim KM. Impact of momordica charantia (karela) on the body weight in the streptozotocin-induced diabetic rat. Bangladesh J Anatomy. 2013;9(2):106-109. doi:10.3329/bja. v9i2.15282

45. Lee W-J, Jang S, Lee S-H, Lee H-S. Correlation between the severity of diabetic peripheral polyneuropathy and glycosylated hemoglobin levels: a quantitative study. Annals of Rehabilitation Medicine. 2016;40(2):263-270. doi:10.5535/arm.2016.40.2.263

46. Limdi JK. Evaluation of abnormal liver function tests. Postgrad Med J. 2003;79(932):307-312. doi:10.1136/pmj.79.932.307

47. Vozarova B, Stefan N, Lindsay RS, et al. High alanine aminotransferase is associated with decreased hepatic insulin sensitivity and predicts the development of type 2 diabetes. Diabetes. 2002;51 (6):1889-1895. doi:10.2337/diabetes.51.6.1889

48. Ngubane PS, Masola B, Musabayane CT. The Effects of Syzygium aromaticum -Derived Oleanolic Acid on Glycogenic Enzymes in Streptozotocin-Induced Diabetic Rats. Ren Fail. 2011;33 (4):434-439. doi:10.3109/0886022X.2011.568147

49. Ros S, García-Rocha M, Calbó J, Guinovart JJ. Restoration of hepatic glycogen deposition reduces hyperglycaemia, hyperphagia and gluconeogenic enzymes in a streptozotocin-induced model of diabetes in rats. Diabetologia. 2011;54(10):2639-2648. doi:10.1007/s00125-011-2238-X

50. Qi M, Wang X, Xu H, Yang Z, Cheng Y, Zhou B. Protective effect of ferulic acid on STZ-induced diabetic nephropathy in rats. Food Funct. 2020;11(4):3706-3718. doi:10.1039/C9FO02398D

51. Kröncke K-D, Fehsel K, Sommer A, Rodriguez M-L, KolbBachofen V. Nitric oxide generation during cellular metabolization of the diabetogenic n-methyl-n-nitroso-urea streptozotozin contributes to islet cell DNA damage. Biological Chemistry HoppeSeyler. 1995;376(3):179-185. doi:10.1515/bchm3.1995.376.3.179
52. Sokolovska J, Isajevs S, Rostoka E, et al. Changes in glucose transporter expression and nitric oxide production are associated with liver injury in diabetes. Cell Biochem Funct. 2015;33(6):367-374. doi: $10.1002 /$ cbf.3123

53. Piwowar A, Knapik-Kordecka M, Warwas M. AOPP and its relations with selected markers of oxidative/antioxidative system in type 2 diabetes mellitus. Diabetes Res Clin Pract. 2007;77(2):188-192. doi:10.1016/j.diabres.2006.12.007

54. Gradinaru D, Borsa C, Ionescu C, Margina D. Advanced oxidative and glycoxidative protein damage markers in the elderly with type 2 diabetes. J Proteomics. 2013;92:313-322. doi:10.1016/j. jprot.2013.03.034

55. Sellamuthu PS, Arulselvan P, Kamalraj S, Fakurazi S, Kandasamy M. Protective nature of mangiferin on oxidative stress and antioxidant status in tissues of streptozotocin-induced diabetic rats. ISRN Pharmacology. 2013;2013:1-10. doi:10.1155/2013/750109

56. Sheweita SA, Mashaly S, Newairy AA, Abdou HM, Eweda SM. Changes in oxidative stress and antioxidant enzyme activities in streptozotocin-induced diabetes mellitus in rats: role of alhagi maurorum extracts. Oxid Med Cell Longev. 2016. doi:10.1155/2016/ 5264064

57. Al-Numair KS, Chandramohan G, Veeramani C, Alsaif MA. Ameliorative effect of kaempferol, a flavonoid, on oxidative stress in streptozotocin-induced diabetic rats. Redox Rep. 2015;20 (5):198-209. doi:10.1179/1351000214Y.0000000117

58. Alkhalidy H, Moore W, Wang Y, et al. The flavonoid kaempferol ameliorates streptozotocin-induced diabetes by suppressing hepatic glucose production. Molecules. 2018;23(9):9. doi:10.3390/ molecules23092338

59. Wang J, Fang X, Ge L, et al. Antitumor, antioxidant and anti-inflammatory activities of kaempferol and its corresponding glycosides and the enzymatic preparation of kaempferol. PLoS One. 2018;13(5):e0197563. doi:10.1371/journal.pone.0197563

60. Inui A, Cheng K-C, Asakawa A, et al. Rosmarinic acid ameliorates hyperglycemia and insulin sensitivity in diabetic rats, potentially by modulating the expression of PEPCK and GLUT4. Drug Des Devel Ther. 2016;10:2193-2202. doi:10.2147/DDDT.S108539

61. Li Y, Zheng X, Yi X, et al. Myricetin: a potent approach for the treatment of type 2 diabetes as a natural class B GPCR agonist. FASEB J. 2017;31(6):2603-2611. doi:10.1096/fj.201601339R

62. Zych M, Wojnar W, Borymski S, Szałabska K, Bramora P, Kaczmarczyk-Sedlak I. Effect of rosmarinic acid and sinapic acid on oxidative stress parameters in the cardiac tissue and serum of type 2 diabetic female rats. Antioxidants. 2019;8(12):12. doi:10.3390/ antiox 8120579
Journal of Inflammation Research

\section{Publish your work in this journal}

The Journal of Inflammation Research is an international, peerreviewed open-access journal that welcomes laboratory and clinical findings on the molecular basis, cell biology and pharmacology of inflammation including original research, reviews, symposium reports, hypothesis formation and commentaries on: acute/chronic inflammation; mediators of inflammation; cellular processes; molecular mechanisms; pharmacology and novel anti-inflammatory drugs; clinical conditions involving inflammation. The manuscript management system is completely online and includes a very quick and fair peerreview system. Visit http://www.dovepress.com/testimonials.php to read real quotes from published authors. 